Spatial Transformation Abilities and their Relation to Later Mathematics Performance

Andrea Frick

University of Bern

NOTICE: This is a post-peer-review, pre-copyedit version of an article published in Psychological Research. Changes resulting from the publishing process, such as editing, corrections, structural formatting, and other quality control mechanisms may not be reflected in this document. This article may be used for non-commercial purposes in accordance with the journal's conditions. The final version is available online at: https://rdcu.be/LbPo

Frick, A. (2019). Spatial transformation abilities and their relation to later academic achievement. Psychological Research, 83(7),1465-1484. DOI: 10.1007/s00426-018-1008-5

Andrea Frick is now at the Department of Psychology of the University of Fribourg, Switzerland. Corresponding address: Andrea Frick, University of Fribourg, Department of Psychology, Rue P.A. de Faucigny 2, CH-1700 Fribourg, Switzerland. Phone: +41 26300 7483. E-mail: depsy@gmx.net ORCID: 0000-0001-6190-0895

Data of this project has been presented at the Society for Research in Child Development (SRCD) biennial meeting, as well as at the 'Space and Mathematics' conference in Chicago in 2015. Some of the data of the first waves of this longitudinal project has been published in two prior publications focusing on the relation between perspective-taking and executive functioning in kindergarten (2016; DOI:

10.1007/s00426-016-0785-y), and between balance skills, spatial, and proportional reasoning (2016; DOI: 10.3389/fpsyg.2015.02049).

Acknowledgments:

This research was supported by a research grant from the Swiss National Science Foundation \# PZ00P1_131866 and \# PP00P1_150486. Special thanks go to Wenke Möhring, Nora S. Newcombe, Laurenz L. Meier, Siegfried Macho, Claudia M. Roebers, Sarah Loher, Marianne Röthlisberger, and Annik E. Voelke for helpful comments, and to Denise Baumeler, Joël E. Bayard, Leunora Fejza, Ines Holzmann, and Lisa Odermatt for their help with data collection. 


\begin{abstract}
Using a longitudinal approach, this study investigated the relational structure of different spatial transformation skills at kindergarten age, and how these spatial skills relate to children's later mathematics performance. Children were tested at three time points, in kindergarten, first grade, and second grade $(N=119)$. Exploratory factor analyses revealed two subcomponents of spatial transformation skills: one representing egocentric transformations (mental rotation and spatial scaling), and one representing allocentric transformations (e.g., cross-sectioning, perspective taking). Structural equation modeling suggested that egocentric transformation skills showed their strongest relation to the part of the mathematics test tapping arithmetic operations, whereas allocentric transformations were strongly related to numeric-logical and spatial functions as well as geometry. The present findings point to a tight connection between early mental transformation skills, particularly the ones requiring a high level of spatial flexibility and a strong sense for spatial magnitudes, and children's mathematics performance at the beginning of their school career.
\end{abstract}

Keywords: development of spatial cognition, spatial transformation, math, geometry, longitudinal study 


\section{Spatial Transformation Abilities and their Relation to Later Mathematics Performance}

\section{Relation between Spatial and Mathematical Thinking}

The ability to flexibly reason about objects and their spatial properties is an important aspect of everyday cognition and of adaptive importance. Spatial skills may also be fundamental for high-level cognitive skills, and in many science disciplines, we use spatial analogies and models to think about complex systems or processes (National Research Council, 2012; Newcombe, 2010). Indeed, research has yielded cross-sectional evidence for a close connection between spatial and scientific reasoning (e.g., physics: Kozhevnikov, Motes, \& Hegarty, 2007; chemistry: Pribyl \& Bodner, 1987; Wu \& Shah, 2004; geology: Orion, Ben-Chaim, \& Kali, 1997; biology: Lennon, 2000), and between spatial and mathematical reasoning in particular (e.g., Casey, Nuttall, Pezaris, \& Benbow, 1995; Kyttälä \& Lehto, 2008; Laski, et al., 2013; Mix et al., 2016; Reuhkala, 2001; for a review, see Mix \& Cheng, 2012).

There are different theoretical accounts that have provided explanations for why spatial and mathematical thinking may be connected. For example, Lakoff and Núñez (2000) posited that mathematical thinking is based on conceptual metaphors that originate from experience in the physical world. This notion is in line with developmental theories that propose a progression from executed actions and sensorimotor experiences (which are inherently spatial) to inner and symbolic imitation (Piaget \& Inhelder, 1966/1971), or from enactive (action-based), to iconic (pictorial) to symbolic (abstract) representations (Bruner, Olver, \& Greenfield, 1966). Thus, experience with objects in the physical space may serve as a basis for spatial-pictorial internal representations, which may then provide the building blocks for abstract thought (cf. representational-development hypothesis, Kosslyn 1978). Similarly, according to the Dahaene's Triple-Code-Model of mathematical reasoning (Dehaene, 1992; Dehaene \& Cohen, 1995) analogue magnitude representations, which are conceptualized as spatial mental representations of numerical magnitude (such as a mental number line), are constitutive for number processing. Other theoretical approaches have posited a general magnitude system as a common mechanism for processing numbers and space (Walsh, 2003; see also Lourenco \& Longo, 2011), which received support from research findings that adults (e.g., Pinel, Piazza, Le Bihan, \& Dehaene, 2004) and 
even infants (de Hevia \& Spelke, 2010) seem to spontaneously map numbers onto space. In this approach, infants begin with a generalized system extending across various dimensions of quantity (e.g., size, volume, number), and these correlated dimensions become increasingly differentiated throughout development.

Indeed, a large number of studies have investigated the relation between spatial abilities and mathematics performance in the past four decades. While some argued that spatial skills are related to high-level mathematics skills only (e.g., Smith, 1964), others have found positive relations to mathematics skills at elementary school level (e.g., Guay \& McDaniel, 1977; Rourke, 1993) or even in children as young as 3 years of age (Verdine et al., 2014). Hegarty and Kozhevnikov (1999) compared mathematics performance in spatial and pictorial visualizers, and found that the use of spatial imagery was associated with success in mathematical problem solving, whereas the use of pictorial imagery, characterized by vivid and detailed visual images, was negatively correlated with success. These findings pointed out that specifically spatial imagery, that is, the ability to represent the spatial relationships between objects and to imagine spatial transformations, may be foundational for mathematical thinking. Mix and Cheng (2012) proposed that spatial transformations may help to visualize numerical magnitudes and to flexibility adjust these mental representations during mathematical operations. Thus, a high level of spatial flexibility might be foundational for performing mathematical operations and spatial abilities may help to assess, visualize, and reorganize magnitudes and their relations (cf. Tartre, 1990).

However, longitudinal studies investigating the relation between spatial abilities and later mathematical skills are still quite rare. One of the few existing longitudinal studies pointed to the importance of adolescents' spatial ability for successful careers in scientific and technical domains (Shea, Lubinski \& Benbow, 2001; Wai, Lubinski \& Benbow 2009) with predictive validity for the number of patents obtained over 30 years later (Kell, Lubinski, Benbow, \& Steiger, 2013). Another study involving high school students revealed that $9^{\text {th }}$ grade girls' ability to visualize how a three-dimensional object (presented two-dimensionally) would look if rotated predicted their geometry and mathematics performance 1 to 3 years later (Sherman, 1979). More recent studies with younger children (Gunderson, 
Ramirez, Beilock, \& Levine, 2012; LeFevre et al., 2013; Verdine, Golinkoff, Hirsh-Pasek, \& Newcombe, 2017) yielded evidence for relations between children's spatial abilities and number-line knowledge, as well as later arithmetic skills. However, these studies differed in the way they assessed spatial skills, and we still know little about which specific spatial skills are relevant for later mathematical understanding and what the relative contributions of different spatial abilities are. Gaining a better understanding of the specific subcomponents of spatial ability, as well as their early developments and consequences for later success in mathematics, could be instrumental for developing purposeful and well-directed interventions.

Thus, in the present study a longitudinal approach was used that assessed a wider range of spatial skills than previous studies in order to investigate (a) the relations among different subcomponents of spatial ability at kindergarten age, and (b) how these pre-school spatial skills would predict children's later mathematics and geometry performance in second grade. Also, in extension of the above longitudinal studies with young children, a standardized math test assessing multiple components of mathematical abilities was used, in order to gain a more differentiated picture of the relation between spatial an mathematical reasoning.

\section{Types of Spatial Transformation Skills}

Lohman (1979) defined spatial ability as the ability to generate, retain, and manipulate abstract visual images. There is strong evidence that spatial ability is not a single construct, but composed of distinct abilities (for a review of factor-analytic approaches, see Hegarty \& Waller, 2005). However, a recent factor-analytic study found no evidence for more than one factor in 5- to 13-year-old children (Mix et al., 2016). What complicates things is that some often-used spatial tasks, like map-reading, may in fact require different spatial skills, such as scaling the map to match the size of the referent space, mentally aligning it with the reference space, recognizing 3D landmarks on the basis of 2D depictions on the map, and understanding how a specific viewpoint of the 3D space is projected onto a 2D representation (Liben \& Downs, 1992). Thus, to date there is no clear consensus regarding the structure and subcomponents of spatial ability (Newcombe \& Shipley, 2015; Uttal, et al. 2013). In the following, some prevalent typologies that have been proposed to categorize adults' spatial skills will be discussed. Most of these 
categorization attempts hinge on the fact that, when thinking about spatial transformations, we need to define a stable point in space, with respect to which a change takes place. Yet, it is still an open question, which of these categorizations apply to children's spatial thinking.

Traditionally, a general distinction has often been drawn in theories on spatial cognition with regard to the reference system (or reference point) in relation to which a spatial change takes place, with a dichotomy between egocentric and allocentric frames of reference (c.f. Klatzky, 1998). In egocentric coding, locations are encoded relative to a coordinate system in which the observer (i.e., the ego) is at the zero-point (or "origin"). In contrast, the term allocentric is used to refer to different types of nonegocentric coding, in which the coordinate system is centered on a reference point external to the observer. Such a reference point could be fixed with respect to the earth, the sun, a star, or even another person. This differentiation between ego- and allocentric coding is also prevalent in the developmental literature (e.g., Acredolo, 1978; Rieser, 1979).

Early psychometric research has suggested a distinction between 'spatial visualization' and 'spatial orientation' (Guilford \& Zimmerman, 1948; McGee, 1979; Thurstone, 1950, for a review, see Hegarty \& Waller, 2004). Spatial visualization refers to the ability to imagine the movements and transformations of objects and spatial forms without reference to one's self (e.g., paper folding, form board test, copying, etc.); spatial orientation refers to the ability to imagine the appearance of objects from different orientations. However, there has been some disagreement as to whether spatial orientation includes changes that are due to movements of an observer (e.g., perspective taking) as well as of an object (e.g., mental rotation), or whether the latter constitutes a separate ability. A later factor-analytic study (Hegarty \& Waller, 2004) for example, showed that measures of perspective taking and mental rotation were highly correlated but also clearly dissociable in adults. Furthermore, experimental research has yielded evidence for pronounced incongruities between observer rotation tasks and tasks that involved object or array rotations in terms of behavioral responses (Huttenlocher \& Presson, 1973, 1979; Simons \& Wang, 1998; Wang \& Simons, 1999; Wraga, Creem, \& Proffitt, 2000) and neurophysiological activation patterns (e.g. Creem et al., 2001; Zacks, Rypma, Gabrieli, Tversky, \& Glover, 1999). 
Accounting for such dissociations and based on an extensive review of factor-analytic research, Lohman (1979) identified a separate factor that reflects mental object movement, as in mental rotation, which he labeled 'spatial relations'. Together with spatial visualization and spatial orientation, he thus assumed that three major factors underlie spatial abilities. These factors could also be described in terms of changes with respect to three different reference frames: During spatial visualization, for example, when folding, stretching, cutting, or combining objects, we change their intrinsic structure or shape and move their parts with respect to an object-centered frame of reference. During spatial orientation, we move our viewpoint with respect to a stable environmental reference frame in order to imagine how a stimulus array looks from a different perspective. Finally, spatial relations tasks involve changing the orientation or location of objects with respect to the observer, who is stable with respect to the environment. Recent neuroimaging data have corroborated these categories, by showing that spatial coding is associated with different brain activity depending on which of these spatial reference frames it bears on (Committeri et al., 2004). Moreover, a recent factory-analytic study (Pittalis \& Christou, 2010) replicated these three factors and found that all of them were predictive for various types of geometrical thinking.

A distinction with regard to reference frames is also reflected in a more recent typology of spatial skills by Uttal and colleagues (2013; see also Newcombe \& Shipley, 2015), who differentiated between extrinsic dynamic spatial skills, such as perspective taking or navigation, and intrinsic dynamic skills, which include transformations that affect the shape, configuration, or arrangement of parts, changes in size (scale), and changes involving two- and three-dimensional views. However, in contrast to the above three-factor structures, egocentric transformations are not treated as a separate category, and skills such as mental rotation are instead considered intrinsic transformations. It seems reasonable to conceptualize mental rotation as belonging to a different category than perspective taking, in light of the above-mentioned evidence for strong dissociations between observer rotation tasks and tasks that involved object or array rotation. Moreover, a study with 9-year-olds (Liben, Myers, Christensen, \& Bower, 2013) showed that perspective-taking but not mental-rotation skills were predictive for their 
ability to find locations in a large environment and relate them to a map. However, previous factoranalytic research (for an overview, see Hegarty \& Waller, 2005) has also suggested that mental rotation was often dissociated from tasks that involved intrinsic shape changes, such as paper folding or form board tests, suggesting that it is different from spatial visualization. Unlike these tasks, mental rotation typically requires transforming the orientation of the whole object (with respect to the observer or another object), while preserving the internal structure and maintaining a constant representation of the shape (or internal configuration) of the object.

To sum up, some approaches group mental rotation with spatial visualization tasks, others subsume it under a spatial orientation factor, yet others assume it constitutes a separate third factor. In light of this uncertainty in the literature about how to categorize mental rotation in particular, and about the structure of spatial skills in general, the relation among different spatial abilities, including mental rotation, was examined in the present study.

A second distinction in the typology by Uttal and colleagues (2013; see also Chatterjee, 2008; Newcombe \& Shipley, 2015) concerns static and dynamic skills. Whereas static skills involve coding of spatial object features, locations, and configurations, dynamic skills involve the transformation of these spatial codings, locations, and interrelations. The present study focused on dynamic spatial skills, based on the literature reviewed above, suggesting that spatial transformations abilities may be especially helpful for mathematical reasoning. In the following sections, the specific spatial transformations skills assessed in the present study, related research findings, and to-be-expected relations to math and geometry performance will be described in more detail.

\section{Extrinsic Reference Frame / Spatial Orientation}

Perspective taking refers to the ability to visualize a change in perspective and infer how a layout would look from another observer's viewpoint, and can be considered a transformation with respect to an extrinsic reference frame. Already infants seem to know that other persons may see other things than themselves (Level 1 perspective taking: Moll \& Tomasello, 2006; Sodian, Thoermer, \& Metz, 2007). However, the ability to compute exactly how another person perceives things (Level 2 perspective taking) 
develops much later, around age 4 or 5 (Flavell, Flavell, Green, \& Wilcox, 1980; Masangkay et al., 1974) and improves considerably between 6 and 8 years of age (Frick, Möhring, \& Newcombe, 2014; Salatas \& Flavell, 1976). There is cross-sectional evidence (e.g., Guay \& McDaniel, 1977) for a correlation between 5th- to 7th-graders' (but not younger children's) performance on a perspective-taking test and their mathematics achievement. Moreover, perspective taking requires what Piaget and Inhelder (1948/1956) called an understanding of projective space, therefore perspective taking could also be expected to relate to geometrical reasoning (e.g., understanding angles, viewpoints, and geometric transformations, such as reflections and translations).

\section{Intrinsic Reference Frame / Spatial Visualization}

Cross-sectioning refers to the ability visualize changes to the internal structure or shape of an object. In the Santa Barbara Solids Test (Cohen \& Hegarty, 2007), participants have to visualize the cross-section of an object after it is cut in two. Ratliff and colleagues (Ratliff, McGinnis, \& Levine, 2010) developed a version of this test that is suitable for children, the Cross-sectioning for Children. Results obtained with this task showed that a basic understanding of cross-sections improved from 3 to 8 years of age. The ability to imagine how something is cut into parts may be helpful for understanding subtraction problems or proportional relations.

Another task that involves shape transformations is the Children's Mental Transformation Task (Levine, Huttenlocher, Taylor, \& Langrock, 1999). It requires the mental combination of two shapes into a whole, and thus could be considered as the reverse operation of cross-sectioning. The ability to mentally combine shapes may be foundational for understanding the concept of addition. Indeed, performance on this task has been shown to correlate to number-line knowledge and symbolic calculations in second grade (Gunderson et al., 2012). Furthermore, training on this task improved 6- to 7-year-olds'

performance on a mathematics test, compared to a control group who solved crossword puzzles (Cheng \& Mix, 2014). More specifically, children's addition and subtraction scores improved, especially on missing operand problems (but see Hawes, Moss, Caswell, \& Poliszczuk, 2015). 
Other transformations that can be considered intrinsic or structural are changes in representational format. Two-dimensional (2D) representations of three-dimensional (3D) objects are commonly used as educational tools, and this trend is increasing, due to changes in publishing practices (Slough, McTigue, Kim, \& Jennings, 2010). According to Piaget and Inhelder (1948/1956) an understanding of how a 3D image can be rendered or „projected“ onto a 2D surface requires the comprehension of projective spatial systems, which develops not until 7 to 8 years of age. Indeed, a study on children's ability to match photographs of objects to the corresponding line drawings using the Diagrammatic Reasoning Task (Frick \& Newcombe, 2015) showed considerable developmental progression between 4 and 8 years of age, but especially around age 6 . Children's understanding of projective spatial systems and the ability to interpret 2D representations of 3D objects may be important prerequisites for geometrical thinking (Pittalis \& Christou, 2010).

\section{Egocentric Reference Frame / Spatial Relations}

Mental rotation refers to the ability to visualize an object in a different orientation. In classic mental rotation tasks, participants were asked to discriminate whether a rotated figure was exactly the same or a mirror image of an upright figure (Shepard \& Metzler, 1971), or to discriminate normal from backward versions of alphanumeric characters that were presented individually in different orientations (Cooper \& Shepard, 1973). There is evidence that mental rotation is present at a very early age in precursory form (e.g., Frick \& Möhring, 2013; Frick \& Wang, 2014; Möhring \& Frick, 2013; Hespos \& Rochat, 1997). However, previous research has also shown that there are vast individual differences in preschoolers' mental rotation abilities, that the ability is far from fully developed by the time of school entry, and that it improves continuously through early childhood (e.g., Estes, 1998; Frick, Ferrara, \& Newcombe, 2013). Cross-sectional developmental studies have shown associations between mental rotation and mathematics performance (Casey et al., 1995; Hegarty \& Kozhevnikov, 1999; Mix et al., 2016; Kyttälä \& Lehto, 2008; Reuhkala, 2001), possibly due to the ability to mentally move and manipulate operands when solving mathematics problems. Furthermore, there is evidence for a relation 
between adolescents' mental rotation and their performance on geometry tests (Battista, 1990; Delgado \& Prieto, 2004).

Spatial scaling - the ability to compare spaces of different size - has been largely ignored by classic research and categorization attempts (Linn \& Peterson, 1985; Voyer, Voyer, \& Bryden, 1995), or only assessed as part of a conglomerate of spatial skills in map reading tasks. Thus, its relation to other spatial skills is still unclear. In Uttal and colleagues' (2013) typology, spatial scaling could be categorized as an intrinsic skill, because object-internal distances are transformed. However, it could also be considered a transformation with regard to the egocentric reference frame (cf. Hegarty \& Waller, 2004), as a spatial size transformation leaves the relative internal structure and configuration of the object or space intact, while changing its apparent size or distance with respect to the observer. Indeed previous research suggested that analog mental transformation similar to mental rotation is used to scale spaces (Möhring, Newcombe, \& Frick, 2014). Some scaling studies also showed poor performance at preschool and kindergarten age (Liben, Moore \& Golbeck, 1982; Siegel \& Schadler, 1977; Uttal, 1996), and performance increased during the preschool years (Frick \& Newcombe, 2012; Vasilyeva \& Huttenlocher, 2004). Developmental research further suggests that children's scaling abilities are closely related to their understanding of proportions (Möhring, Newcombe, \& Frick, 2015). However, little is known about the relation of spatial scaling to mathematics achievement in general. In the present study, a positive relation between spatial scaling skills and later performance on a standardized math test was expected, based on the assumption that scaling involves similar processes as mental rotation.

\section{Present Study}

A first goal of the present study was to clarify the structural relations among different subcomponents of spatial ability at kindergarten age. The second goal was to determine which of these pre-school spatial skills would predict children's later mathematics and geometry performance at the beginning of children's school careers.

The spatial transformations skills described above were measured in kindergarten at age 6 , based on previous results (Frick, Hansen, \& Newcombe, 2013; Frick et al., 2014; Frick \& Newcombe, 
2015; Ratliff et al., 2010) that children showed-above chance performance but still large individual differences in various spatial transformation skills at this age. Aside from spatial measures, basic calculation skills and some control variables were assessed in order to account for general differences in age, cognitive abilities (verbal IQ), or socio-economic background.

In first grade, some possible mediator variables, such as non-spatial and visuo-spatial working memory (WM), number-line knowledge, and proportional reasoning were assessed, in light of previous research suggesting that these abilities might play a crucial role in linking spatial and mathematical skills (e.g., Booth \& Siegler, 2008; Hansen et al., 2015; Reeve, Paul, \& Butterworth, 2015; Siegler \& Booth, 2004). More specifically, Möhring and colleagues (Möhring et al., 2015; Möhring, Newcombe, Levine, \& Frick, 2016) found that proportional reasoning correlates to spatial scaling as well as to formal fraction knowledge. Moreover, Gunderson and colleagues (2012) showed that the ability to locate whole numbers on a line measured at age 6 mediated the relation between spatial skills at age 5 and symbolic calculation at age 8. Visual-spatial WM has been shown to be correlated to spatial visualization (Shah \& Miyake, 1996) as well as predictive for mathematical ability (Bull, Espy, \& Wiebe, 2008; Raghubar, Barnes, \& Hecht, 2010), and van Dijck and Fias (2011) proposed that visuo-spatial WM may play a crucial role in the formation of spatial-numerical associations. These variables were assessed at $\mathrm{T} 2$ in order to replicate previous research that used a similar staggered design (Gunderson et al., 2012). The present study sought to further investigate these relations using a wider range of spatial and mathematical tests. As mediation processes typically unfold over time, a staggered design, in which some time elapses between predictors, mediators, and outcome variables, is suitable to test mediation effect (Maxwell \& Cole, 2007).

Academic achievement, in terms of mathematics, geometry, and reading performance, was assessed in second grade. Spatial transformation skills were expected to be predictive for mathematics and geometry performance. Reading performance was additionally assessed to investigate the specificity of a potential relation between spatial and math or geometry skills. Mental rotation skills were assessed at all three time points using different tasks, in order to gain information about the stability of this prototypical spatial skill during the course of the study. 


\section{Method}

\section{Participants}

Children were recruited in 24 different rural and urban kindergartens in the German speaking part of Switzerland towards the end of the school year, a few months before entering primary school. Written parental consents and children's verbal assents were obtained from 140 children (62 girls, 78 boys) at a mean age of 6.47 years. The same children were tested again in first and second grade (at a mean age of 7.53 and 8.26 years, respectively), except for 21 children, of which 3 had moved away, 4 were absent on the day of assessment, and 14 did not return parental consent forms. The final sample for which complete data sets were available consisted of 119 children $(51$ girls, mean age $=8.26$ years, $S D=0.30$, range $=$ $7.74-8.86 ; 68$ boys, mean age $=8.25, S D=0.36$, range $=7.72-8.98)$.

\section{General Procedure}

The first assessment (T1) took place near the end of kindergarten, a few months before children transitioned to primary school. It consisted of two test sessions that were approximately 1-2 weeks apart and lasted about 30 minutes each $(M=10.4$ days; $S D=8.5$ days $)$. Children were tested individually in a separate room at their kindergarten. Materials were presented on a table, and the experimenter was seated orthogonally to the side of the participant. The second assessment (T2) was administered near the end of first grade and children were again tested individually in a separate room. Testing took about 30 to 40 minutes. The third assessment (T3) consisted of group tests that were administered during two successive school lessons near the end of second grade. After each session, children received a small toy or a snack and were praised regardless of their performance. Table 1 gives an overview of the tested abilities and the order in which the tasks were administered - some variables (e.g., fine- and gross-motor skills) that were included in the longitudinal study but not the focus of the present paper are omitted for the sake of conciseness.

\section{T1 Measures}


Mental Rotation was assessed with the Ghost Rotation Task (Frick, Hansen, \& Newcombe, $2013^{1}$ ). This task presented two ghosts that were mirror images of each other. Children were asked to pick the ghost that would fit into a hole (see Fig. 1a). There were 21 items with varying ghost shapes that were presented in 7 different orientations. All spatial transformation tasks (unless mentioned otherwise) were scored with one point for each item that was solved correctly.

The Perspective-Taking Task for Children (Frick et al., 2014) assessed children's ability to imagine another observer's viewpoint. Children saw color printouts showing toy photographers taking pictures of objects, and were asked to choose among four pictures which one the toy photographer could have taken from a particular angle (see Fig. 1b). There were 22 items with varying viewing angles and different numbers of objects in the layout.

In the Cross-sectioning for Children (Ratliff et al., 2010), pictures of 3D geometric solids were presented, which were intersected by a cardboard piece indicating where the objects would be cut in two. Children were asked to select the resulting cross-section among four alternatives. This task had 12 items showing different geometric solids and intersection angles.

${ }^{1}$ Test-retest reliability measures are reported where available; however, for some of the tasks, such measures were unobtainable. Measures based on inter-item correlations are misleading in these tasks, as items differ considerably in difficulty. For example, accuracy on items requiring mental rotation by a large angle is significantly lower than items requiring only a small mental transformation (Frick, Hansen, et al., 2013). Nevertheless, for the sake of completeness, Guttman's Lambda 2 was calculated in these cases and were as follows: Ghost Rotation: .70; Perspective Taking: .70; Cross-sectioning: .56; Children's Mental Transformation Task: .75; Diagrammatic Representations: .69; Proportional Reasoning: .88; Number-Line Task: .87. For span tasks (both working memory tasks) and timed tasks (Card Rotation, Geometry Task), inter-item correlations are meaningless as children solved different numbers of items. 
In the Children's Mental Transformation Task (Levine et al., 1999) children were presented with two black 2D shapes. They were asked what kind of shape the two pieces would form if they were moved together and to choose among four alternatives. An abbreviated version with 24 items was used. Half of the items required the two pieces to be translated horizontally and rotated $60^{\circ}$ to form the target shape; the other half required a diagonal translation but no rotation.

The Diagrammatic Representations Task (Frick \& Newcombe, 2015) assessed children's understanding of translations between representational formats ${ }^{2}$. Children saw photographs of 3D objects that had to be matched with 2D line drawings, or vice-versa (see Fig. 1c). Children chose among four choice-alternatives, and the task consisted of 24 items.

The Spatial Scaling Task (Frick \& Newcombe, 2012) assessed children's understanding of size transformations ${ }^{1}$. Children were presented with 24 small maps showing a target (see Fig. 1e) and asked to locate the target in a larger field. Items varied in scaling factor and shape of the fields. Responses were scored with respect to how close they were to the targets $(1 / 3,2 / 3$, or 1 point for responses within $2 \mathrm{~cm}$, $1.5 \mathrm{~cm}$, or $1 \mathrm{~cm}$, respectively).

The passive and active vocabulary subtests of the HAWIVA-III (Ricken, Fritz, Schuck, \& Preuss, 2007; German translation of WIPPSI-III) were administered as a measure of verbal (i.e., nonspatial) $I Q$ (test-retest reliability reported in the test manual: .72 and .83 , respectively). Children saw four pictures and were asked to point to the one that the experimenter named; or they were shown a picture

${ }^{2}$ In the case of map reading, changes in scale typically go hand in hand with changes in representational format, as maps typically are scaled two-dimensional representations of a three-dimensional space. In order to disentangle these two transformations, the Spatial Scaling Task used in the present study did not involve any changes in format - conversely, the Diagrammatic Reasoning Task did not involve changes in scale. 
and asked to name it actively. Scores were summed across passive and active vocabulary subtests and transformed into a verbal IQ score according to test norms.

Basic calculation skills were measured by putting some marbles into a box with a lid. Marbles were then added or taken out and children were asked to guess how many marbles were left in the box. There were 3 subtraction and 3 addition problems (all single digit) and children received 1 point for every correct response.

Socio-economic Status (SES) was assessed by means of a parent questionnaire, based on parent's occupations, which were coded using the 'International Standard Classification of Occupation' (ISCO-88, International Labor Office, 1990) and transformed into the 'International Socio-Economic Index' (ISEI: Ganzeboom, De Graaf, Treiman, \& De Leeuw, 1992), which ranges from 16 to 90. The higher index of the mothers or fathers was used. If neither parent indicated a current occupation, the ISEI of the occupations they were trained for was used instead. SES of all but $3(2.5 \%)$ of the 119 children was determined. Occupation rather than income or education was used as an index for SES, as PISA results (OECD, 2013) suggest that parents' highest occupational status explains more variance in children's mathematics performance than education or cultural possessions, and because the ISCO and ISEI codes provide an internationally comparable and continuous measure of SES.

\section{T2 Measures}

Visuo-spatial working memory was assessed using the Position Span Task (Frick \& Möhring, 2016), which requires memory for sequential spatial information. Children saw the head of a groundhog popping up for 2 seconds in different locations on a green 4 by 4 grid on a laptop monitor. Then, children were asked to point on the empty grid to where they had seen the animal popping up in backward order. The length of these sequences started at two and was increased by one after every third trial (to a maximum of seven target locations). After more than two mistakes per difficulty level the task was terminated. Each sequence that was reproduced in the correct order was credited with one point (the maximum possible points was 21 ). 
Non-spatial Working Memory was assessed using the Backward Color Recall Task (Schmid, Zoelch, \& Roebers, 2008; test-retest reliability reported in the original publication with 4-and 5-year-olds: .57). Children saw sequences of colored circles (yellow, blue, red, green, brown, black) that were presented for one second in the center of a white computer screen. Then, children were asked to name the colors in backward order. The length of these sequences started at two and was increased by one after every third trial (to a maximum of seven). After two or more mistakes per difficulty level the task was terminated. Each sequence that was reproduced in the correct order was credited with one point (the maximum possible points was 21).

Proportional Reasoning was measured with a task adapted from Möhring et al. (2015). Children were presented with combinations of red and blue rectangles representing cherry juice and water, and were asked to estimate the cherry taste of each mixture by drawing a mark on a rating scale. The task had 18 items that presented different combinations of juice $(2,4,6$ units) and water $(3,6,9$ units). The locations of the marks on the rating scale were measured (in $\mathrm{mm}$ ). To account for individual usage of the rating scale, responses were standardized by dividing the raw responses by each child's individual standard deviation (ipsatization, Hicks, 1970; Möhring et al., 2015). The mean deviations of these values from the normative values served as an index for children's proportional reasoning skills.

Children's number knowledge was measured using the Number Line task (Siegler \& Opfer, 2003), presenting the same numbers as Ebersbach, Luwel, Frick, Onghena, and Verschaffel (2007; Set B). Children saw a horizontal line $(15 \mathrm{~cm})$ that was labeled " 0 " at its left and " 100 " at its right end. On each of 15 trials, a number was presented to the left of the line and children were asked to mark where this number belonged on the number line. The locations of the marks were measured (in $\mathrm{mm}$ ) and their mean absolute deviations from the normative values served as a performance score.

Mental rotation was assessed again at T2, using the Card Rotations Test (CRT; Ekstrom, French, Harman, \& Dermen, 1976). This test presented rows of eight 2D figures. Children were asked to decide whether each figure was the same or the mirror image of a standard figure presented to the left of each row. To adapt it to the age of the present sample, eight rows (rather than the original 20) were 
presented, and completion time was reduced to $4 \mathrm{~min}$. (rather than $6 \mathrm{~min}$.). A score was calculated by subtracting the number of figures marked incorrectly from the number of figures marked correctly.

\section{T3 Measures}

At T3, mental rotation was assessed again using the Figure Rotation subtest of the SchaieThurstone Adult Mental Abilities Test (Schaie, 1985; test-retest reliability $=.81$ in adults over three years). The test presented rows of six 2D figures, and children had to decide whether each figure was the same or the mirror image of a standard figure presented to the left of each row. Twenty rows were presented and completion time was limited to 5 minutes. Scoring was analogous to the Card Rotation Test.

To assess geometry skills, children were given a task in which they were asked to select the shapes they would need to construct a geometric solid (e.g., cylinder, cone, etc., see Fig. 1d) from a set of seven 2D shapes, as well as to indicate how many of these shapes they would need. This task was designed specifically for this study, as no age-adequate group test of early geometry skills was available. In this geometric construction task, children had to pay attention to geometric properties of 3D objects, like surface shapes and circumferences, and also take into account how the appearance of the shapes change under geometric transformations (e.g., surface development). The task had 16 items and completion time was limited to 3 minutes. Correctly solved items were credited with 1 point. Mathematics skills were assessed using the Heidelberger Rechentest for grades 1 through 4 (HRT 1-4, Haffner, Baro, Parzer, \& Resch, 2005). This test consists of two subscales, one of which measures ‘Arithmetic Operations' (addition, subtractions, missing operands, and bigger/smaller comparison problems; test-retest reliability $=.93$ ), thus assessing an understanding of basic arithmetic operations, mathematical symbols, equations, and computation skills that are thought to be foundational for the development of complex mathematic competencies. The other subscale measures 'NumericLogical and Spatial Functions' (completing number sequences, counting magnitudes, counting cubes, estimating line lengths; test-retest reliability $=.87$ ), and thus assesses the processing of quantities and magnitudes as well as the recognition of logical structures and numerical regularities. Correctly solved 
items were transformed into a separate score for each subscale and a composite score according to the test norms.

Reading skills were measured using the Salzburg Lese Screening (SLS 1-4, Mayringer \& Wimmer, 2003; test-retest reliability $=.92$ ), in which children had to judge whether short German sentences were true or false. It was scored how many sentences children judged correctly within 3 minutes; incorrect responses were subtracted.

\section{Results}

In the following, descriptive statistics and outlier analyses will be reported first, followed by an analysis of possible sex differences in the assessed variables, due to a long-standing debate in the spatial literature about the size and origins of sex differences (for a review see Voyer et al., 1995). After giving an overview of bivariate and partial correlations (controlled for age, verbal IQ, and SES) a factor analysis will be reported that was performed to find out whether the different spatial skills that were assessed in this study are manifestations of a singular ability, or which different components of spatial ability can be distinguished. This information on the relational structure of spatial transformation skills served as the basis for analyses using Structural Equation Modeling (SEM). In these SEM analyses, it was tested how the factor structure of spatial skills in kindergarten (= measurement model) can predict school achievement in second grade (= structural model). Finally, after determining a basic (minimal) structural model, it was tested whether adding variables that were likely candidates for mediator variables based on previous literature would improve the model.

\section{Outliers Analyses, Descriptive Statistics, and Sex Differences}

Each variable was analyzed for outliers and values that were more than 2.5 standard deviations above or below the mean were excluded ( 1 to 6 values per variable, mean $=2.6$ values or $2.2 \%$ ). Table 1 shows descriptive statistics for all variables after outliers were removed. Based on Q-Q plots, all variables showed normal distributions, except for basic calculation, which showed a ceiling effect. 
To test for possible sex differences, a MANOVA was calculated with the variables in Table 1 as dependent variables and sex as independent variable. Multivariate tests showed no significant effect of sex, $F<1$. Therefore, and because sex differences were not a focus of this study, this variable was not considered in subsequent analyses.

\section{Correlations Analyses}

Table 2 shows the Pearson correlations between the variables of interest. Zero-order correlations (below diagonal) showed that mathematics, geometry and reading performance were correlated to SES. However, except for perspective taking, no significant correlations were found between spatial skills and SES. The latter result contrasts previous reports of SES differences in spatial skills (Levine, Vasilyeva, Lourcenco, Newcombe, and Huttenlocher, 2005; Verdine, Golinkoff, Hirsh-Pasek, Newcombe, Filipowicz, \& Chang, 2014; Verdine, Irwin, Golinkoff, \& Hirsh-Pasek, 2014), but are in line with other reports of no significant relations between parent education or income and spatial transformation skills (Levine, Ratliff, Huttenlocher, \& Cannon, 2012). A number of differences between the studies could account for the discrepant findings. For example, previous studies were conducted in the United States and used different measures, such as parent income or education, to assess SES. However, these differences are unlikely to fully explain the discrepancy, in light of results from the PISA study (OECD, 2013) showing that the US and Switzerland actually show very similar profiles with respect to effects of SES on mathematics performance. The PISA results also showed that parents' highest occupational status explained even more variance in performance than level of education, wealth, or cultural possessions. Another explanation might be found in the level at which socio-economic status was assessed. Whereas in the present study, as well as in the study by Levine and colleagues (2012), SES was assessed at the individual level, other studies assessed SES at the school level (Levine et al. 2005; Casey, et al 2008), or low and high SES children were predominantly recruited at head-start or private preschools, respectively (Verdine, Golinkoff, et al., 2014). The PISA data (OECD, 2013) suggests, that the variance in mathematics performance explained by individual students' socio-economic backgrounds within schools is much smaller that the variance explained by the attended schools' SES. 
Partial correlations (above diagonal) showed that after controlling for age, verbal IQ, and SES, spatial transformation skills assessed in kindergarten (T1) were positively correlated to mathematics and/or geometry scores in second grade (T3), but not to reading scores. Furthermore, Card Rotation test performance, number-line knowledge, and visuo-spatial WM measured in first grade (T2) and Figure Rotation performance measured in second grade (T3) were positively correlated to mathematics and geometry performance in second grade (T3). Mental rotation skills, as measured by the tests Ghost Rotation at T1, Card Rotation at T2, and Figure Rotation at T3, were correlated across the three time points, suggesting some stability in this ability. Furthermore, after controlling for age, verbal IQ, and SES none of these measures of mental rotation were related to performance on the Children's Mental Transformation Task, suggesting that these tasks measure distinct abilities.

\section{Exploratory Factor Analysis}

In order to answer the first research question and determine the number of factors that best reflected the data structure among spatial transformation skills measured at T1, parallel analysis (O’Connor, 2000) was used, which is based on Monte Carlo simulation. Parallel analysis (principal axis factoring, $95^{\text {th }}$ percentile, number of datasets $=5000$ ) suggested a 2 -factor solution (with the eigenvalues of 1.35 and 0.33 ). An exploratory factor analysis (see Table 3 for Structure Matrix; Oblimin rotation) showed that mental rotation loaded highly on the first factor, spatial scaling loaded similarly on both factors, whereas diagrammatic representation, cross-sectioning, mental transformation (as measured by the Children's Mental Transformation Task), and perspective taking clearly loaded highest on the second factor. The two factors will subsequently referred to as ST1 and ST2.

Two further analyses were preformed to test the robustness of this solution. In a first analysis, the two mental rotation measures Card Rotation and Figure Rotation, assessed at T2 and T3 respectively, were added. Parallel analysis again suggested 2 factors (with eigenvalues of 1.84 and 0.75 ). The two additional mental rotation measures also loaded highest on ST1, with factor loadings of .563 and .871 , respectively, and the factor structure of the first analysis was replicated. Thus, even when mental rotation measures were included that spanned all three measurement time points, mental rotation consistently 
loaded highest on ST1. Another exploratory factor analysis was performed with all available T1 data, including 18 additional children who provided complete T1 data but dropped out before the final assessment. Parallel analysis suggested 2 factors (with eigenvalues of 1.49 and 0.31). Again, this analysis confirmed the general structure of the first analysis, with all variables except mental rotation and spatial scaling loading highest on ST2. However, in this analysis, spatial scaling loaded clearly higher on ST1 (.532) than ST2 (.443).

Finally, a factor analysis was performed in order to test whether the factor structure suggested by the authors of the standardized mathematics test (HRT 1-4, Haffner et al., 2005) could be replicated within the sample of the present study. Parallel analysis indeed suggested 2 factors (with eigenvalues of 2.54 and 0.55$)$. The factor analysis confirmed that the tests of the subscale 'Arithmetic Operations' (addition, subtractions, missing operands, and bigger/smaller comparison problems) loaded highest on the first factor (all loadings $>.525$ ), whereas the tests of the subscale 'Numeric-Logical and Spatial Functions' (completing number sequences, counting magnitudes, counting cubes, estimating line lengths) loaded highest on the second factor (all loadings $>.531$ ).

\section{Structural Equation Modeling (SEM)}

In a next step, SEM was used (on IBM SPSS AMOS 22, Arbuckle, 2013) to further clarify the relationship between the spatial variables and later school achievement. Model fit was determined on the basis of the chi-square value, the Tucker-Lewis Index (TLI), the Comparative Fit Index (CFI), and the root mean squared error of approximation (RMSEA). According to Hu and Bentler $(1998,1999)$ a good model fit is indicated by a non-significant $\chi^{2}$ value, TLI and CFI values above .95 , and an RMSEA value of less than .06. Parsimony was determined based on of Akaike's Information Criterion (AIC) - lower values indicate more parsimonious models. No multivariate outliers were identified (all Mahalanobis distances $<27, p>.017$ ), and Cook's distances $($ all $<.079)$ revealed no influential data points. Collinearity could be ruled out (all VIF $<1.8$, tolerance $>.57$ ). Based on Mardia's test, multivariate normality could be assumed (multivariate kurtosis $<7$, c.r. $<1.96$ ) thus Maximum Likelihood estimates 
were used. A basic model will be presented first, followed by extended models that tested the role of control variables and possible mediator variables.

A first basic model was built, including all spatial transformation abilities as well as the outcome variables of mathematics and geometry. Following the original structure of the standardized mathematics test, the two subcomponents of Arithmetic Operations and Numeric-Logical and Spatial Functions were retained. Based on the factor analysis reported above, two latent variables ST1 and ST2 were assumed to underlie the spatial variables. Paths with very low standardized regression weights between ST2 and Arithmetic Operations $(\beta=-.07, p=.75)$ and between ST1 and Geometry $(\beta=-.13, p=$ .36) were removed. The resulting basic model (see Fig. 2$)$ had an excellent fit $\left(\chi_{(83)}^{2}=84.953, p=.42\right.$, $\mathrm{TLI}=.993, \mathrm{CFI}=.995, \mathrm{RMSEA}=.014, \mathrm{AIC}=188.95)$. The latent variable ST1, representing mental rotation and spatial scaling, was predictive for Arithmetic Operations $(\beta=.50, p<.01)$ as well as for Numeric-Logical and Spatial Functions $(\beta=.35, p=.027)$. ST2 significantly predicted Numeric-Logical and Spatial Functions $(\beta=.41, p<.01)$ and Geometry performance $(\beta=.63, p<.001)$. ST1 accounted for $24 \%$ of the variance in Arithmetic Operations, ST2 for $40 \%$ of the variance in Geometry performance, and ST1 and ST2 together explained a total of $43 \%$ of the variance in Numeric-Logical and Spatial Functions.

Based on high cross loadings of scaling in the above factor analysis, scaling could also be grouped with the ST2 variables. However, an alternative model with spatial scaling as an indicator for ST2 resulted in a lower model fit with regard to all indices $\left(\chi^{2}{ }_{(83)}=102.372, p=.073, \mathrm{TLI}=.930, \mathrm{CFI}=\right.$ $.952, \mathrm{RMSEA}=.044, \mathrm{AIC}=206.372$ ), and the higher AIC value indicated a less parsimonious model. Likewise, an alternative model with just one spatial transformation factor representing all six spatial transformation tasks proved to be inferior with regards to model fit and parsimony $\left(\chi^{2}{ }_{(85)}=104.675, p=\right.$ $.073, \mathrm{TLI}=.931, \mathrm{CFI}=.951, \mathrm{RMSEA}=.044, \mathrm{AIC}=204.675)$. The lower fit of these alternative models further confirmed that the 2-factor solution obtained from the above factor analysis described the data best. 
Next, T1 control variables (age, verbal IQ, SES) as well as children's basic calculation skills at T1 were added to the model, to test whether these variables were influencing the relation between the spatial and outcome variables in the model. After paths with low regression weights were removed (all $\beta \mathrm{s}$ between -.13 and $+.11, p \mathrm{~s}>.27$ ), SES showed no more connections to any of the variables. Therefore SES was removed from the model, which resulted in a good fit $\left(\chi_{(122)}^{2}=128.710, p=.321, \mathrm{TLI}=.980\right.$, $\mathrm{CFI}=.986, \mathrm{RMSEA}=.022, \mathrm{AIC}=262.71)$. Figure 3 shows the basic model (in black) including the remaining control variables (in grey). Basic calculation skills at T1 were predictive for Geometry and math skills, whereas verbal IQ was related to ST2 only. There was a positive relation of age to ST2 performance in kindergarten, but a negative relation to Numeric-Logical and Spatial Functions at T3. In this controlled model, the same paths between latent and outcome variables remained significant, indicating that the structure of the model was not strongly affected by adding the control variables to the model. However, the explained variance in Arithmetic Operations (34\%), Numeric-Logical and Spatial Functions (67\%), and Geometry (50\%) increased.

Finally, the role of possible mediator variables that were assessed at T2 was investigated. Visuospatial WM, non-spatial WM, proportional reasoning and number-line knowledge were added to the model as possible mediators between the latent and the outcome variables. Proportional reasoning, number-line knowledge, and non-spatial WM did not show significant relations to neither of the predictor and outcome variables when added to the model (see Table 4, last three rows) indicating that the indirect paths via these variables were not significant, and thus these variables were ruled out as possible mediators. Visuo-spatial WM was significantly related to ST1 as well as to both mathematics subtests (see Table 4, first row), and therefore qualified as a possible mediator variable. When visuo-spatial WM was included in the model, the direct path between ST1 and Arithmetic Operations remained significant $(\beta=.37, p=.039)$, whereas the direct path between ST1 and Numeric-Logical and Spatial Functions was no longer significant $(\beta=.23, p=.136)$. However, adding visuo-spatial WM to the model resulted in a 
lower model fit, a trend to a significant $\chi^{2}$ value, and a large loss of parsimony $\left(\chi_{(137)}^{2}=163.539, p=.061\right.$, $\mathrm{TLI}=.931, \mathrm{CFI}=.950, \mathrm{RMSEA}=.041, \mathrm{AIC}=307.539)$; therefore, this mediation model was rejected

\section{Discussion}

The two main goals of the present study were to investigate (a) the structural relations among dynamic spatial transformation skills in kindergarten, and (b) the role of these early spatial transformation skills for children's later mathematics performance. Several spatial transformation abilities were measured in kindergarten, along with control variables and children's basic calculation skills. Some additional abilities that likely contributed to spatial and/or mathematical thinking based on previous literature (e.g., Gunderson et al., 2012; Hansen et al., 2015; Möhring et al., 2016; Raghubar et al., 2010; Reeve, et al., 2015; Siegler \& Booth, 2004) were assessed in first grade. Children's mathematics, geometry, and reading performance was assessed at the end of second grade.

\section{Relations among Spatial Transformation Abilities}

To shed light on the question of which subcomponents of spatial ability can be distinguished, an exploratory factor analysis was performed. Results suggested a two-factor structure, with a first factor representing mental rotation and spatial scaling, and a second factor that included perspective taking, diagrammatic representations, cross-sectioning, and the Children's Mental Transformation Task. These two factors and the groups of tasks they represent align with two of the spatial factors proposed by Lohman (1979): 'Spatial Relations' and 'Spatial Visualization', which refer to the abilities to imagine the movements and transformations of objects and spatial forms with and without reference to one's self, respectively. In that sense, the two factors can also be labeled "egocentric" and "allocentric", in line with a general distinction between egocentric and allocentric frames of reference in spatial thinking (Klatzky, 1998). This distinction is of major theoretical importance and has been largely recognized in spatial as well as developmental literature. The present findings thus strongly indicate that a separate conceptualization of observer-related (egocentric) spatial transformations may be of great practical relevance.

The result that egocentric skills constituted a factor separate from other intrinsic spatial 
transformation skills is in line with previous factor-analytic approaches (e.g., Lohman, 1979; for overviews, see Hegarty \& Waller, 2005; Linn \& Petersen, 1985), which differentiated mental rotation from other spatial tasks such as paper folding, form board, or block design that require transformations of object-internal relations. Moreover, mental rotation and perspective taking measures did not load on the same factor in the present study, suggesting that they represent dissociable skills, in line with findings from factor-analytic (Hegarty \& Waller, 2004), behavioral (Huttenlocher \& Presson, 1973; Simons \& Wang, 1998; Wraga et al., 2000) and neurophysiological research (e.g. Creem et al., 2001; Zacks et al., 1999). However, contrary to previous analyses of factor-analytic research in adults (Hegarty \& Waller, 2005; Lohman, 1979) perspective taking was not differentiated from intrinsic spatial transformations in the present study with kindergarten children. This suggests that whether the transformation occurred relative to an environment-centered or object-centered reference frame was less distinctive at this age than whether the reference point was internal or external to the observer.

The finding of two separate spatial factors seem at odds with previous results from a study showing that spatial tasks converged on a single factor in 5- to 13-year-old children (Mix et al., 2016). However, there are some differences between the studies that might account for these discrepant findings. One difference lies in how the appropriate number of factors was determined in the previous and the present study (eigenvalue-greater-than-one rule vs. parallel analysis, respectively). A second factor that just missed the cut-off criterion (eigenvalue of .97) for kindergarteners in the previous study might have been identified with the repeated random sampling approach used in the present study. A further possible reason for discrepant findings lies in a different selection of spatial task. For example, some of the spatial tasks tested in the previous study tapped complex spatial skills (e.g., map reading requiring scaling, rotation, and 2D-3D translations), whereas the present study aimed to separate the skills as much as possible. The 2-factor solution suggested by repeated random sampling method in the present study was further corroborated by the finding that a structural equation model with only one spatial factor did not result in a good model fit, whereas a 2 -factor solution described the data well.

One spatial skill that was isolated in this study but has not received much attention in previous 
research is spatial scaling. Spatial scaling loaded equally on both factors in the initial factor analysis. However, it clearly loaded more strongly on the first factor in a subsequent analysis that was based on all available data (including data of children who had dropped out after T1). High cross-loading of spatial scaling may indicate that different strategies were at play: On the one hand, scaling can be thought of as a transformation that changes object-internal absolute distances. On the other hand, object-internal relative distances are preserved during spatial scaling, thus the relational spatial structure of an object remains the same. Moreover, there is evidence (Möhring et al., 2014) that children and adults solve scaling tasks by means of analog mental transformations, akin to mental rotation. Participants may mentally expand the object (or "zoom" in on it), thus changing the apparent size (or distance) of the object with respect to themselves as the observers (cf. Newcombe, Möhring, \& Frick, in press). On this account, spatial scaling could be conceptualized as a transformation in relation to the egocentric reference frame, and classified alongside mental rotation. The findings of the factor analyses and a better fit of the structural equation model if scaling was grouped with mental rotation support this idea.

\section{Relations between Spatial Transformation Abilities and Later Mathematics and Geometry Performance}

A basic SEM model reflecting the 2-factor structure determined in the factor analysis of spatial tasks and the two math factors suggested by the constructors of the math test represented the data well, as indicated by an excellent fit of the basic model. The spatial variables accounted for a large part of the variance in children's mathematics and geometry performance $(24-43 \%)$. Inclusion of children's verbal IQ, age, and basic calculation skill in kindergarten resulted in a good model fit. Basic calculation skills particularly increased the explained variance in children's mathematics and geometry skills two years later. Age was positively related to ST2 only, which is not surprising as the age range was only about one year. To control for IQ, a deliberately non-spatial measure (verbal IQ) was used, which was only related to ST2, but did not contribute to the variance in ST1 or the outcome variables. SES was not related to any of the latent variables or the outcome variables and thus was not included in the final model. Of the mediator variables tested, only visuo-spatial WM qualified as a potential mediator variable by showing at 
least one significant indirect path leading from a spatial latent variable to the mediator and from the mediator variable to an outcome variable. However, including visuo-spatial WM as a mediator resulted in a lower model fit and a large loss of parsimony, therefore the simpler model without mediators was retained as the final model.

Both the final SEM model including control variables, as well as the more parsimonious basic model indicated that the latent variable ST1, reflecting mental rotation and spatial scaling (i.e., the abilities to visualize an object in a different orientation or size), was a strong predictor for children's mathematics scores at the end of second grade. It also specified that these egocentric transformation skills were particularly related to Arithmetic Operations, but also significantly predicted performance on the math subtests that measured Numeric-Logical and Spatial Functions. The latent variable ST2, reflecting perspective taking, diagrammatic representations, cross-sectioning, and performance on the Children's Mental Transformation Task, was predictive for geometry scores as well as for performance on the Numeric-Logical and Spatial Functions subtests in second grade.

A possible basis for a connection between mental rotation and mathematical thinking is, that in order to solve mathematical equations, one often has to "move" operands in ones mind. For example, to solve the missing operands problem $\{?+2=10\}$ one may mentally reverse the problem into $\{10-2=?\}$. Furthermore, mental rotation tasks such as the ones used in the present study require the participants to recognize spatial symmetry. Figuring out how to create symmetry in an equation, or balancing out what is on the left and right of an equal sign, is an important accomplishment in mathematics. Mental rotation may thus be an index of the ability to flexibly move operands mentally to solve mathematics problems (cf. Mix \& Cheng, 2012).

Spatial scaling may be important for mathematical thinking, as the ability to reason about spatial sizes and to flexibly transform them in one's mind may be essential for understanding other kinds of magnitudes such as numerical magnitudes. Previous research (Möhring et al., 2015) has shown that scaling is related to proportional reasoning, suggesting that scaling ability is an important basis for understanding relative size or proportion. The present findings extend these results by showing that 
spatial scaling bears an even wider relevance, as it was predictive for children's performance on a standardized mathematics assessment that covered several areas of mathematical thinking. This also highlights that spatial scaling deserves more attention in developmental research, with regards to its importance for children's performance in mathematics and other science disciplines.

One result that may be somewhat surprising is that ST1, reflecting mental rotation and spatial scaling, did not predict geometry performance. Bivariate correlations actually yielded some significant relations between geometry and spatial scaling as well as mental rotation, as measured by the card rotation and figure rotation tests, suggesting that these skills are not completely unrelated. However, the moderate correlations between ST1 variables and geometry might have been outweighed by the even stronger correlations between ST2 variables and geometry in the SEM analysis.

Perspective taking, diagrammatic representations, cross-sectioning, and performance on the Children's Mental Transformation Task, were predictive for geometry scores and Numeric-Logical and Spatial Functions. Perspective taking and diagrammatic reasoning require an understanding of what Piaget and Inhelder (1948/1956) called 'projective' space, and the ability to interpret 2D representations of 3D objects may thus be integral to geometric thinking (Pittalis \& Christou, 2010). Moreover, the abilities to take apart or combine objects in one's mind may be used when analyzing components and identifying surfaces of the presented geometric solids. These spatial transformation skills may thus also be particularly important for mathematical subdomains that have a spatial aspect, such as counting magnitudes and cubes, estimating line lengths, and completing sequences. Future studies with older participants may investigate the relation between spatial and mathematical skills and other mathematical subdomains, such as analysis, set theory, statistics, or differential geometry.

\section{Conclusions}

Taken together, the results of the present study yield corroborating longitudinal evidence for a strong link between spatial skills in kindergarten and children's mathematics and geometry performance in second grade. They extend previous longitudinal findings of associations between adolescents' spatial abilities and their later careers in scientific and technical domains (Shea, Lubinski \& Benbow, 2001; Wai, 
Lubinski \& Benbow 2009) by showing that spatial abilities are already predictive for mathematical thinking at the beginning of the school career. Furthermore, they extend previous evidence for links between spatial and numerical skills at an early age (Gunderson et al., 2012; LeFevre et al., 2013), by specifying which spatial skills are predictive for different subcomponents of mathematical abilities.

The present findings provide support for theoretical accounts positing that the ability to form spatial representations may provide comprehensible spatial analogues for abstract mathematical terms (Lakoff \& Núñez, 2000; Dehaene, 1992), and that a strong sense for spatial magnitudes may be associated with a better understanding of numerical magnitudes (Walsh, 2003). Furthermore, they are in line with the notions that the structure of mathematical problems may be realized through a spatial format and that spatial skills may be used to visualize and reorganize mathematical relationships (for a review see Tartre, 1990). A high level of spatial flexibility may thus be foundational for performing mathematical operations (cf. Mix \& Cheng, 2012).

Even though the correlational nature of the present data does not allow for causal conclusions, the present results are in line with and extend contemporary findings of a longitudinal study in 3- to 5year-olds (Verdine et al., 2017), suggesting that a close link between spatial and mathematical skills does exist, emerges early, and is likely causally related. Furthermore, although training studies are rare, there is recent evidence for a causal link between spatial and mathematical performance (Cheng \& Mix, 2014), as training with the Children's Mental Transformation Task improved 6- to 7-year-olds' addition and subtraction scores on missing operand problems. The present results indicate that even larger gains might be expected if trainings included mental rotation and spatial scaling.

Spatial skills have been largely ignored or minimized in early education (Clements \& Sarama, 2011), despite their broad relevance and ample evidence that they can be trained (Uttal et al., 2013). For example, Sorby (2009) showed that middle school students profited form a spatial workbook that trained 3D drawing and spatial skills such as mental rotation, scaling, and cross-sectioning. Sorby also suggested that interventions at high school age may be too late especially for girls, because poor self-efficacy beliefs are already established, and that earlier interventions may be more fruitful. Promoting spatial thinking and 
providing opportunities to practice these mental transformation skills early in life might have a large potential for creating long-term positive effects on performance in mathematical and geometrical disciplines, and possibly even in a wide range of science disciplines that build on these foundations. 


\section{Compliance with Ethical Standards}

Ethical approval: All procedures performed in studies involving human participants were in accordance with the ethical standards of the institutional and/or national research committee and with the 1964 Helsinki declaration and its later amendments or comparable ethical standards. Procedures were approved by the Institutional Review Board of the University. The manuscript does not contain clinical studies or patient data.

Informed consent: Informed consent was obtained for all individual participants included in the study.

Conflict of Interest: The author declares that she has no conflict of interest.

Data availability: The datasets of the current study are available from the corresponding author upon reasonable request. 


\section{References}

Arbuckle, J. L. (2013). IBM SPSS Amos 22 user's guide. Crawfordville, FL: Amos Development Corporation.

Acredolo, L. P. (1978). Development of spatial orientation in infancy. Developmental Psychology, 14, 224-234. doi: 10.1037/0012-1649.14.3.224

Battista, M. (1990). Spatial visualization and gender differences in high school geometry. Journal for Research in Mathematics Education, 21, 47-60 doi:10.2307/749456

Booth, J. L., \& Siegler, R. S. (2008). Numerical magnitude representations influence arithmetic learning. Child Development, 79, 1016-1031. doi:10.1111/j.1467-8624.2008.01173.x

Bruner, J. S., Olver, R. R., \& Greenfield, P. M. (1966). Studies in cognitive growth. New York: Wiley. doi:10.3102/00028312005001117

Bull, R., Espy, K. A., \& Wiebe, S. A. (2008). Short-term memory, working memory, and executive functioning in preschoolers: Longitudinal predictors of mathematical achievement at age 7 years. Developmental Neuropsychology, 33, 205-228. doi: 10.1080/87565640801982312

Casey, B. M., Andrews, N., Schindler, H., Kersh, J. E., Samper, A., \& Copley, J. (2008). The development of spatial skills through interventions involving block building activities. Cognition and Instruction, 26, 269-309. doi: 10.1080/07370000802177177

Casey, M. B., Nuttall, R. L., Pezaris, E., \& Benbow, C. P. (1995). The influence of spatial ability on gender differences in math college entrance test scores across diverse samples. Developmental Psychology, 31, 697-705. doi:10.1037/0012-1649.31.4.697

Chatterjee A. (2008). The neural organization of spatial thought and language. Seminars in Speech and Language, 29, 226-238. iscepidoi:10.1055/s-0028-1082886

Cheng, Y. L., \& Mix, K. S. (2014). Spatial training improves children's mathematics ability. Journal of Cognition and Development, 15, 2-11. doi:10.1080/15248372.2012.725186

Clements, D. H., \& Sarama, J. (2011). Early childhood teacher education: The case of geometry. Journal of Mathematics Teacher Education, 14, 133-148. doi:10.1007/s10857-011-9173-0

Cohen, C. A., \& Hegarty, M. (2007). Sources of difficulty in imagining cross sections of 3D objects. In Proceedings of the Twenty-Ninth Annual Conference of the Cognitive Science Society (pp. 179- 
184). Cognitive Science Society Austin TX.

Committeri, G., Galati, G., Paradis, A. L., Pizzamiglio, L., Berthoz, A., \& LeBihan, D. (2004). Reference frames for spatial cognition: Different brain areas are involved in viewer-, object-, and landmarkcentered judgments about object location. Journal of Cognitive Neuroscience, 16, 1517-1535. doi:10.1162/0898929042568550

Cooper, L. A., \& Shepard, R. N. (1973). The time required to prepare for a rotated stimulus. Memory and Cognition, 1, 246-250. doi:10.3758/bf03198104

Creem, S. H., Downs, T. H., Wraga, M., Harrington, G. S., Proffitt, D. R., \& Downs, J. H., III. (2001). An fMRI study of imagined self-rotation. Cognitive, Affective and Behavioral Neuroscience, 1, 239249. doi:10.3758/CABN.1.3.239

de Hevia, M. D. \& Spelke, E. S. (2010). Number-space mapping in human infants. Psychological Science, 21, 653-660. doi:10.1177/0956797610366091

Dehaene, S. (1992). Varieties of numerical abilities. Cognition, 44, 1-42. doi:10.1016/00100277(92)90049-N

Dehaene, S., \& Cohen, L. (1995). Towards an anatomical and functional model of number processing. In B. Butterworth \& L. Cipolotti (Eds.), Mathematical cognition, Vol 1, 83-120.

Delgado, A. R., \& Prieto, G. (2004). Cognitive mediators and sex-related differences in mathematics. Intelligence, 32, 25-32. doi:10.1016/s0160-2896(03)00061-8

Ebersbach, M., Luwel, K., Frick, A., Onghena, P., \& Verschaffel, L. (2007). The relationship between the shape of the mental number line and familiarity with numbers in 5- to 9-year old children: Evidence for a segmented linear model. Journal of Experimental Child Psychology, 99, 1-17. doi:10.1016/j.jecp.2007.08.006

Ekstrom, R. B. R., French, J. J. W., Harman, H. H., \& Dermen, D. (1976). Manual for kit of factorreferenced cognitive tests. Princeton NJ Educational Testing Service, 102, 117. doi:10.1073/pnas.0506897102

Estes, D. (1998). Young children's awareness of their mental activity: The case of mental rotation. Child Development, 69, 1345-1360. doi:10.2307/1132270

Flavell, J. H., Flavell, E. F., Green, F. L., \& Wilcox, S. A. (1980). Young children's knowledge about 
visual perception: Effect of observer's distance from target on perceptual clarity of target. Developmental Psychology, 16, 10-12. doi:10.1037/0012-1649.16.1.10

Frick, A., Ferrara, K., \& Newcombe, N. S. (2013). Using a touch screen paradigm to assess the development of mental rotation between $3 \frac{1}{2}$ and 51/2 years of age. Cognitive Processing, 14, 117127. doi:10.1007/s10339-012-0534-0

Frick, A., Hansen, M. A., \& Newcombe, N. S. (2013). Development of mental rotation in 3- to 5-year-old children. Cognitive Development, 28, 386-399. doi:10.1016/j.cogdev.2013.06.002

Frick, A., \& Möhring, W. (2013). Mental object rotation and motor development in 8-and 10-month-old infants. Journal of Experimental Child Psychology, 115, 708-720. doi:10.1016/j.jecp.2013.04.001

Frick, A., \& Möhring, W. (2016). A matter of balance: Motor control is related to children's spatial scaling and proportional reasoning skills. Frontiers in Psychology, 6:2049. doi:10.3389/fpsyg.2015.02049

Frick, A., Möhring, W., \& Newcombe, N. S. (2014). Picturing perspectives: Development of perspectivetaking abilities in 4- to 8-year-olds. Frontiers in Psychology, 5:386. doi:10.3389/fpsyg.2014.00386

Frick, A., \& Newcombe, N. S. (2012). Getting the big picture: Development of spatial scaling abilities. Cognitive Development, 27, 270-282. doi: 10.1016/j.cogdev.2012.05.004

Frick, A., \& Newcombe, N. S. (2015). Young children's perception of diagrammatic representations. Spatial Cognition \& Computation, 15, 227-245. doi:10.1080/13875868.2015.1046988

Frick, A., \& Wang, S. (2014). Mental spatial transformations in 14- and 16-month-old infants: Effects of action and observational experience. Child Development, 85, 278-293. doi:10.1111/cdev.12116

Ganzeboom, H. B. G., De Graaf, P. M., Treiman, D. J., \& De Leeuw, J. (1992). A standard international socio-economic index of occupational status. Social Science Research, 21, 1-56. doi:10.1016/0049-089X(92)90017-B

Guay, R. B., \& McDaniel, E. D. (1977). The relationship between mathematics achievement and spatial abilities among elementary school children. Journal for Research in Mathematics Education, 8, 211-215. doi:10.2307/748522

Guilford, J. P., \& Zimmerman, W. S. (1948). The Guilford-Zimmerman Aptitude Survey. Journal of 
Applied Psychology, 32, 24-32. doi:10.1037/h0063610

Gunderson, E. A., Ramirez, G., Beilock, S. L., \& Levine, S. C. (2012). The relation between spatial skill and early number knowledge: The role of the linear number line. Developmental Psychology, 48(5), 1229-1241. doi:10.1037/a0027433

Haffner, J., Baro, K., Parzer, P., \& Resch, F. (2005). Heidelberger Rechentest (HRT 1-4). Göttingen: Hogrefe.

Hansen, N., Jordan, N. C., Fernandez, E., Siegler, R. S., Fuchs, L., Gersten, R., \& Micklos, D. (2015). General and math-specific predictors of sixth-graders' knowledge of fractions. Cognitive Development, 35, 34-49. doi:10.1016/j.cogdev.2015.02.001

Hawes, Z., Moss, J., Caswell, B., \& Poliszczuk, D. (2015). Effects of mental rotation training on children's spatial and mathematics performance: A randomized controlled study. Trends in Neuroscience and Education, 4, 60-68. doi: 10.1016/j.tine.2015.05.001

Hegarty, M., \& Kozhevnikov, M. (1999). Types of visual-spatial representations and mathematical problem solving. Journal of Educational Psychology, 91, 684-689. 0663.91 .4 .684

Hegarty, M., \& Waller, D. (2004). A dissociation between mental rotation and perspective-taking spatial abilities. Intelligence, 32, 175-191. doi:10.1016/j.intell.2003.12.001

Hegarty, M., \& Waller, D. (2005). Individual differences in spatial abilities. In P. Shah \& A. Miyake (Eds.), The Cambridge handbook of visuospatial thinking (pp. 121-169). Cambridge University Press. doi:10.1017/CBO9780511610448.005

Hespos, S. J., \& Rochat, P. (1997). Dynamic mental representation in infancy. Cognition, 64, 153-188. doi:10.1016/s0010-0277(97)00029-2

Hicks, L. E. (1970). Some properties of ipsative, normative, and forced-choice normative measures. Psychological Bulletin, 74, 167-184. doi.10.1037/h0029780

Hu L. \& Bentler, P. M. (1998). Fit indices in covariance structure modeling: Sensitivity to underparameterized model misspecification. Psychological Methods, 3, 424-453. doi:10.1037//1082-989x.3.4.424

Hu L. \& Bentler, P. M. (1999). Cutoff criteria for fit indexes in covariance structure analysis: 
Conventional criteria versus new alternatives. Structural Equation Modeling, 6, 1-55. doi:10.1080/10705519909540118

Huttenlocher, J., \& Presson, C. C. (1973). Mental rotation and the perspective problem. Cognitive Psychology, 4, 277-299. doi:10.1016/0010-0285(73)90015-7

Huttenlocher, J., \& Presson, C. C. (1979). The coding and transformation of spatial information. Cognitive Psychology, 11, 375-394. doi:10.1016/0010-0285(79) 90017-3

International Labour Office (Ed.). (1990). International standard classification of occupations. ISCO1988. International Labour Office: Geneva.

Klatzky, R. L. (1998). Allocentric and egocentric spatial representations: Definitions, distinctions, and interconnections. In C. Freksa, C. Habel, \& K. F. Wender (Eds.), Spatial cognition I-An interdisciplinary approach to representing and processing spatial knowledge (pp. 1-17). Springer, Heidelberg: Berlin. doi: 10.1007/3-540-69342-4_1

Kosslyn, S. M. (1978). The representational-development hypothesis. In P. A. Ornstein (Ed.), Memory development in children (pp. 157-189). Hillsdale, NJ: Erlbaum. doi:10.4324/9781315794266

Kell, H. J., Lubinski, D., Benbow, C. P., \& Steiger, J. H. (2013). Creativity and technical innovation: Spatial ability's unique role. Psychological Science, 24, 1831-1836. doi:10.1177/0956797613478615

Kozhevnikov, M., Motes, M. A., \& Hegarty, M. (2007). Spatial visualization in physics problem solving. Cognitive Science, 31, 549-579. doi:10.1080/15326900701399897

Kyttälä, M., \& Lehto, J. E. (2008). Some factors underlying mathematical performance: The role of visuospatial working memory and non-verbal intelligence. European Journal of Psychology of Education, 23, 77-94. doi:10.1007/BF03173141

Lakoff, G., \& Núñez, R. (2000). Where mathematics comes from: How the embodied mind bring mathematics into being. New York: Basic Books.

Laski, E. V., Casey, B. M., Yu, Q., Dulaney, A., Heyman, M., \& Dearing, E. (2013). Spatial skills as a predictor of first grade girls' use of higher level arithmetic strategies. Learning and Individual Differences, 23, 123-130. doi: 10.1016/j.lindif.2012.08.001

LeFevre, J. A., Lira, C. J., Sowinski, C., Cankaya, O., Kamawar, D., \& Skwarchuk, S. L. (2013). Charting 
the role of the number line in mathematical development. Frontiers in Psychology, 4:641. doi:10.3389/fpsyg.2013.00641

Lennon, P. A. (2000). Improving students' flexibility of closure while presenting biology content. American Biology Teacher, 62, 177-180. doi:10.1662/0002-7685(2000)062[0177:isfocw]2.0.co;2

Levine, S. C., Huttenlocher, J., Taylor, A., \& Langrock, A. (1999). Early sex differences in spatial skill. Developmental Psychology, 35, 940-949. doi:10.1037/0012-1649.35.4.940

Levine, S. C., Ratliff, K. R., Huttenlocher, J., \& Cannon, J. (2012). Early puzzle play: A predictor of preschoolers' spatial transformation skill. Developmental Psychology, 48, 530. doi:/10.1037/a0025913

Levine, S. C., Vasilyeva, M., Lourenco, S. F., Newcombe, N. S., \& Huttenlocher, J. (2005). Socioeconomic status modifies the sex difference in spatial skill. Psychological Science, 16, 841845. doi: 10.1111/j.1467-9280.2005.01623.x

Liben, L. S., \& Downs, R. M. (1992). Developing an understanding of graphic representations in children and adults: The case of GEO-graphics. Cognitive Development, 7, 331-349. doi: 10.1016/08852014(92)90020-R

Liben, L. S., Moore, M. L., \& Golbeck, S. L. (1982). Preschoolers' knowledge of their classroom environment: Evidence from small-scale and life-size spatial tasks. Child Development, 53, $1275-$ 1284. doi:10.1111/j.1467-8624.1982.tb04166.x

Liben, L. S., Myers, L. J., Christensen, A. E., \& Bower, C. A. (2013). Environmental-Scale Map Use in Middle Childhood: Links to Spatial Skills, Strategies, and Gender. Child Development, 84(6), 2047-2063. doi:10.1111/cdev.12090

Linn, M. C., \& Petersen, A. C. (1985). Emergence and characterization of sex differences in spatial ability: A meta-analysis. Child Development, 56, 1479-1498. doi:10.2307/1130467

Lohman, D. F. (1979). Spatial ability: A review and reanalysis of the correlational literature. Aptitude Research Project (Technical Report No. 8). Stanford CA: Stanford University, School of Education.

Lourenco, S. F., \& Longo, M. R. (2011). Origins and development of generalized magnitude representation. In S. Dehaene \& E. M. Brannon (Eds.), Space, time, and number in the brain: 
Searching for the foundations of mathematical thought (pp. 225-244). London: Elsevier.

Masangkay, Z. S., Mccluskey, K. A., Mcintyre, C. W., Sims-Knight, J., Vaughn, B. E., \& Flavell, J. H. (1974). The early development of inferences about the visual percepts of others. Child Development, 45, 357-366. doi:10.2307/1127956

Mayringer, H., \& Wimmer, H. (2003). Salzburger Lese-Screening für die Klassenstufen 1-4 (SLS 1-4). Bern: Hans Huber.

Maxwell, S., \& Cole, D. (2007). Bias in cross-sectional analyses of longitudinal mediation. Psychological Methods, 12, 23-44. doi:10.1037/1082-989X.12.1.23

McGee, M. G. (1979). Human spatial abilities: Psychometric studies and environmental, genetic, hormonal, and neurological influences. Psychological Bulletin, 86, 889-918 doi:10.1037/0033-2909.86.5.889

Mix, K. S. \& Cheng, Y.-L. (2012). The relation between space and math: Developmental and educational implications. In J. B. Benson (Ed.), Advances in child development and behavior (Vol. 42, pp. 197-243). San Diego, CA: Academic Press. doi:10.1016/B978-0-12-394388- 0.00006-X

Mix, K. S., Levine, S. C., Cheng, Y-L., Young, C., Hambrick, D. Z., Ping, R., \& Konstantopoulos, S. (2016). Separate but correlated: The latent structure of space and mathematics across development. Journal of Experimental Psychology: General, 145, 1206-1227. doi:10.1037/xge0000182

Möhring, W., \& Frick, A. (2013). Touching up mental rotation: Effects of manual experience on 6month-old infants' mental object rotation. Child Development, 84, 1554-1565. doi:10.1111/cdev.12065

Möhring, W., Newcombe, N. S. \& Frick, A. (2014). Zooming in on spatial scaling: Preschool children and adults use mental transformations to scale spaces. Developmental Psychology, 50, 16141619. doi:10.1037/a0035905

Möhring, W., Newcombe, N. S., \& Frick, A. (2015). The relation between spatial thinking and proportional reasoning in preschoolers. Journal of Experimental Child Psychology, 132, 213-220. doi:10.1016/j.jecp.2015.01.005

Möhring, W., Newcombe, N. S., Levine, S. C., \& Frick, A. (2016). Spatial proportional reasoning is 
associated with formal knowledge about fractions. Journal of Cognition and Development, 17, 67-84. doi:10.1080/15248372.2014.996289

Moll, H., \& Tomasello, M. (2006). Level I perspective-taking at 24 months of age. British Journal of Developmental Psychology, 24, 603-613. doi:10.1348/026151005X55370

National Research Council (2012). A Framework for K-12 Science Education: Practices, Crosscutting Concepts, and Core Ideas. Committee on a Conceptual Framework for New K-12 Science Education Standards. Board on Science Education, Division of Behavioral and Social Sciences and Education. Washington, DC: The National Academies Press.

Newcombe, N. S. (2010). Picture this: Increasing math and science learning by improving spatial thinking. American Educator, 34, 29-43.

Newcombe, N. S., Möhring, W., \& Frick, A. (in press). How big is many? Development of spatial and numerical magnitude understanding. In A. Henik \& W. Fias (Eds.), Heterogeneity of function in numerical cognition.

Newcombe, N. S., \& Shipley, T. F. (2015). Thinking about spatial thinking: New typology, new assessments. In J. S. Gero (Ed.), Studying visual and spatial reasoning for design creativity (pp. 179-192). New York, NY: Springer. doi:10.1007/978-94-017-9297-4_10

O'Connor, B. P. (2000). SPSS and SAS programs for determining the number of components using parallel analysis and Velicer's MAP test. Behavior Research Methods, Instrumentation, and Computers, 32, 396-402. doi:10.3758/bf03200807

OECD - Organisation for Economic Co-operation and Development (2013). PISA 2012 results: Excellence through equity: Giving every student the chance to succeed (Volume II). OECD, Paris, France. doi:10.1787/9789264201132-en

Orion, N., Ben-Chaim, D., \& Kali, Y. (1997). Relationship between earth-science education and spatial visualization. Journal of Geoscience Education, 45, 129-132. doi:10.5408/1089-9995-45.2.129

Piaget, J., \& Inhelder, B. (1956). The child's conception of space (F. J. Langdon \& J. L. Lunzer, Trans.). New York: Norton. (Original work published 1948).

Piaget, J., \& Inhelder, B. (1971). Mental imagery in the child; a study of the development of imaginal representation (P. A. Chilton, Trans.). New York: Basic. (Original work published 1966). 
Pinel, P., Piazza, M., Le Bihan, D., \& Dehaene, S. (2004). Distributed and overlapping cerebral representations of number, size, and luminance during comparative judgments. Neuron, 41, 983993. doi:10.1016/s0896-6273(04)00107-2

Pittalis, M., \& Christou, C. (2010). Types of reasoning in 3D geometry thinking and their relation with spatial ability. Educational Studies in Mathematics, 75, 191-212. doi:10.1007/s10649-010-9251-8

Pribyl, J. R., \& Bodner, G. M. (1987). Spatial ability and its role in organic chemistry: A study of four organic courses. Journal of Research in Science Teaching, 24, 229-240. doi:10.1002/tea.3660240304

Raghubar, K. P., Barnes, M. A., \& Hecht, S. A. (2010). Working memory and mathematics: A review of developmental, individual difference, and cognitive approaches. Learning and Individual Differences, 20, 110-122. doi:10.1016/j.lindif.2009.10.005

Ratliff, K. R., McGinnis, C. R., \& Levine, S. C. (2010, August). The development and assessment of cross-sectioning ability in young children. Paper submitted to the $32^{\text {nd }}$ Annual Conference of the Cognitive Science Society. Portland, OR.

Reeve, R. A., Paul, J. M., \& Butterworth, B. (2015). Longitudinal changes in young children's 0-100 to 0-1000 number-line error signatures. Frontiers in Psychology, 6:647. doi:10.3389/fpsyg.2015.00647

Reuhkala, M. (2001). Mathematical skills in ninth-graders: Relationship with visuo-spatial abilities and working memory. Educational Psychology, 21, 387-399. doi:10.1080/01443410120090786

Ricken, G., Fritz, A., Schuck, K. D., \& Preuss, U. (2007). HAWIVA-III: Hannover-WechslerIntelligenztest für das Vorschulalter - III. Bern: Huber.

Rieser, J. J. (1979). Spatial orientation of six-month-old infants. Child Development, 50, 1078-1087. doi: $10.2307 / 1129334$

Rourke, B. P. (1993). Arithmetic disabilities, specific and otherwise: A neuropsychological perspective. Journal of Learning Disabilities, 26, 214-226. doi:10.1177/002221949302600402

Salatas, H., \& Flavell, J. H. (1976). Perspective taking: The development of two components of knowledge. Child Development, 47, 103-109. doi:10.2307/1128288

Schaie, K. W. (1985). Schaie-Thurstone adult mental abilities test. Consulting Psychologists Press. 
Schmid, C., Zoelch, C., \& Roebers, C. M. (2008). Das Arbeitsgedächtnis von 4-bis 5-jährigen Kindern. Zeitschrift für Entwicklungspsychologie und Pädagogische Psychologie, 40, 2-12. doi:10.1026/0049-8637.40.1.2

Shah, P., \& Miyake, A. (1996). The separability of working memory resources for spatial thinking and language processing: An individual differences approach. Journal of Experimental Psychology: General, 125, 4-27. doi: 10.1037/0096-3445.125.1.4

Shea, D. L., Lubinski, D., \& Benbow, C. P. (2001). Importance of assessing spatial ability in intellectually talented young adolescents: A 20-year longitudinal study. Journal of Educational Psychology, 93, 604-614. doi:10.1037/0022-0663.93.3.604

Shepard, R. N., \& Metzler, J. (1971). Mental rotation of three-dimensional objects. Science, 171, 701 703. doi:10.1126/science.171.3972.701

Sherman, J. (1979). Predicting mathematics performance in high school girls and boys. Journal of Educational Psychology, 71, 242. doi:10.1037/0022-0663.71.2.242-249.

Siegel, A., \& Schadler, M. (1977). The development of young children's spatial representations of their classrooms. Child Development, 48, 388-394. SỆ: doi:10.2307/1128631

Siegler, R. S., \& Booth, J. L. (2004). Development of numerical estimation in young children. Child Development, 75, 428-444. doi:10.1111/j.1467-8624.2004.00684.x

Siegler, R. S., \& Opfer, J. E. (2003). The development of numerical estimation: Evidence for multiple representations of numerical quantity. Psychological Science, 14, 237-243. doi:10.1111/14679280.02438

Simons, D. J., \& Wang, R. F. (1998). Perceiving real-world viewpoint changes. Psychological Science, 9 , 315-320. doi: 10.1111/1467-9280.00062

Slough, S. W., McTigue, E. M., Kim, S., \& Jennings, S. K. (2010). Science textbooks' use of graphical representation: A descriptive analysis of four sixth grade science texts. Reading Psychology, 31, 301-325. doi:1080/02702710903256502

Smith, I. M. (1964). Spatial ability: Its educational and social significance. San Diego: Knapp. doi: $10.2307 / 3119049$

Sodian, B., Thoermer, C., \& Metz, U. (2007). Now I see it but you don't: 14-month-olds can represent 
another person's visual perspective. Developmental Science, 10, 199-204. doi:10.1111/j.14677687.2007.00580.x

Sorby, S. (2009). Developing spatial cognitive skills among middle school students. Cognitive Processing, 10 (Suppl 2), 312-315. doi: 10.1007/s10339-009-0310-y

Tartre, L. A. (1990). Spatial orientation skill and mathematical problem solving. Journal for Research in Mathematics Education, 21, 216-229. doi: 10.2307/749375

Thurstone, L. L. (1950). Some primary abilities in visual thinking (Rep. no. 59). Chicago, IL: Psychometric Laboratory, University of Chicago

Uttal, D. H. (1996). Angles and distances: Children's and adults' reconstruction and scaling of spatial configurations. Child Development, 67, 2763-2779. doi:10.1111/j.1467-8624.1996.tb01887.x

Uttal, D. H., Meadow, N. G., Tipton, E., Hand, L. L., Alden, A. R., Warren, C., \& Newcombe, N. S. (2013). The malleability of spatial skills: A meta-analysis of training studies. Psychological Bulletin, 139, 352. doi:10.1037/a0028446

van Dijck, J. P., \& Fias, W. (2011). A working memory account for spatial-numerical associations. Cognition, 119, 114-119. doi: 10.1016/j.cognition.2010.12.013

Vasilyeva, M., \& Huttenlocher, J. (2004). Early development of scaling ability. Developmental Psychology, 40, 682-690. doi:10.1037/0012-1649.40.5.682

Verdine, B. N., Golinkoff, R. M, Hirsh-Pasek, K., \& Newcombe, N. S. (2017). Links between spatial and mathematical skills across the preschool years. Monographs of the Society for Research in Child Development, 82, 1-150. doi: 10.1111/mono.12280

Verdine, B. N., Golinkoff, R. M., Hirsh-Pasek, K., Newcombe, N. S., Filipowicz, A. T., \& Chang, A. (2014). Deconstructing building blocks: Preschoolers' spatial assembly performance relates to early mathematical skills. Child Development, 85, 1062-1076. doi: 10.1111/cdev.12165

Verdine, B. N., Irwin, C. M., Golinkoff, R. M., \& Hirsh-Pasek, K. (2014). Contributions of executive function and spatial skills to preschool mathematics achievement. Journal of Experimental Child Psychology, 126, 37-51. doi: 10.1016/j.jecp.2014.02.012

Voyer, D., Voyer, S., \& Bryden, M. P. (1995). Magnitude of sex differences in spatial abilities: A metaanalysis and consideration of critical variables. Psychological Bulletin, 117, 250-270. 
doi:10.1037/0033-2909.117.2.250

Wai, J., Lubinski, D., \& Benbow, C. (2009). Spatial ability for STEM domains: Aligning over 50 years of cumulative psychological knowledge solidifies its importance. Journal of Educational Psychology, 101, 817-835. doi:10.1037/a0016127

Walsh, V. (2003). A theory of magnitude: Common cortical metrics of time, space, and quantity. Trends in Cognitive Sciences, 7, 483-488. doi:10.1016/j.tics.2003.09.002.

Wang, R. F., \& Simons, D. J. (1999). Active and passive scene recognition across views. Cognition, 70, 191-210. doi: 10.1016/S0010-0277(99)00012-8

Wraga, M., Creem, S. H., \& Proffitt, D. R. (2000). Updating displays after imagined object and viewer rotations. Journal of Experimental Psychology: Learning, Memory, and Cognition, 26, 151-168. doi: $10.1037 / 0278-7393.26 .1 .151$

Wu, H.-K., \& Shah, P. (2004). Exploring visuospatial thinking in chemistry learning. Science Education, 88, 465-492. doi:10.1002/sce.10126

Zacks, J. M., Rypma, B., Gabrieli, J. D. E., Tversky, B., \& Glover, G. H. (1999). Imagined transformations of bodies: An fMRI investigation. Neuropsychologia, 37, 1029-1040. doi:10.1016/S0028-3932(99)00012-3 


\section{Figure Captions}

Fig. 1 Examples of stimuli in the a) Ghost Rotation, b) Perspective Taking, c) Diagrammatic Representations, d) Geometry, and e) Spatial Scaling tasks. Note that in the Spatial-Scaling task, the map showed a target object, which is hardly visible in this reproduction

Fig. 2 Basic structural equation model. All indicated paths are significant at $p<.05$ and nonsignificant paths were removed. ST1 \& ST2 = Spatial Transformation Factors $1 \& 2 ; \mathrm{AO}=$ Arithmetic Operations; NLSF $=$ Numeric-Logical and Spatial Functions; $\mathrm{T} 1=$ first measurement time point (kindergarten); $\mathrm{T} 3=$ third measurement time point $\left(2^{\text {nd }}\right.$ grade $)$.

Fig. 3 Structural equation model including control variables. All indicated paths are significant at $p<.05$ and non-significant paths were removed. ST1 \& ST2 = Spatial Transformation Factors $1 \& 2$; $\mathrm{AO}=$ Arithmetic Operations; NLSF $=$ Numeric-Logical and Spatial Functions; $\mathrm{T} 1=$ first measurement time point (kindergarten); T3 = third measurement time point $\left(2^{\text {nd }}\right.$ grade $)$. 
Table 1

Overview of assessment time points (T1-T3), measured abilities, and descriptives.

\begin{tabular}{llccc}
\hline & & range & mean & SD \\
\hline T1 - 6.5 yrs & Perspective Taking & $4-17$ & 9.5 & 2.75 \\
(Session 1) & Mental Rotation (Ghost Rotation) & $11-21$ & 17.8 & 2.51 \\
& Diagrammatic Representation & $12-24$ & 19.1 & 2.51 \\
& Verbal-IQ (active vocabulary) & $78-121$ & $101^{*}$ & 9.26 \\
(Session 2) & Cross-sectioning & $5-12$ & 8.6 & 1.59 \\
& Spatial Scaling & $8.0-21.3$ & 15.0 & 2.76 \\
& Verbal-IQ (passive vocabulary) & $78-121$ & $101 *$ & 9.26 \\
& Mental Transformation & $11-24$ & 19.4 & 3.03 \\
& Basic Calculation & $3-6$ & 5.5 & .85 \\
\hline T2-7.5 yrs & Proportional Reasoning & $0.3-2.1$ & 1.1 & 0.38 \\
& Visuo-spatial WM & $1-11$ & 6.6 & 2.03 \\
& Non-spatial WM & $2-10$ & 6.0 & 1.67 \\
& Number Line & $5.9-33.6$ & 16.5 & 6.70 \\
& Mental Rotation (Card Rotation) & $-6-64$ & 30.2 & 14.30 \\
\hline T3-8.3 yrs & Mathematics (Composite Score) & $34-68.3$ & 53.1 & 6.08 \\
& Mental Rotation (Figure Rotation) & $2-110$ & 53.9 & 22.24 \\
& Reading & $5-54$ & 27.9 & 10.86 \\
& Geometry & $0-10$ & 4.3 & 2.35 \\
\hline Socio-economic Status (ISEI) & $23-88$ & 57.1 & 15.73 \\
\hline
\end{tabular}

* Values for combined active and passive vocabulary subtests. 
Table 2

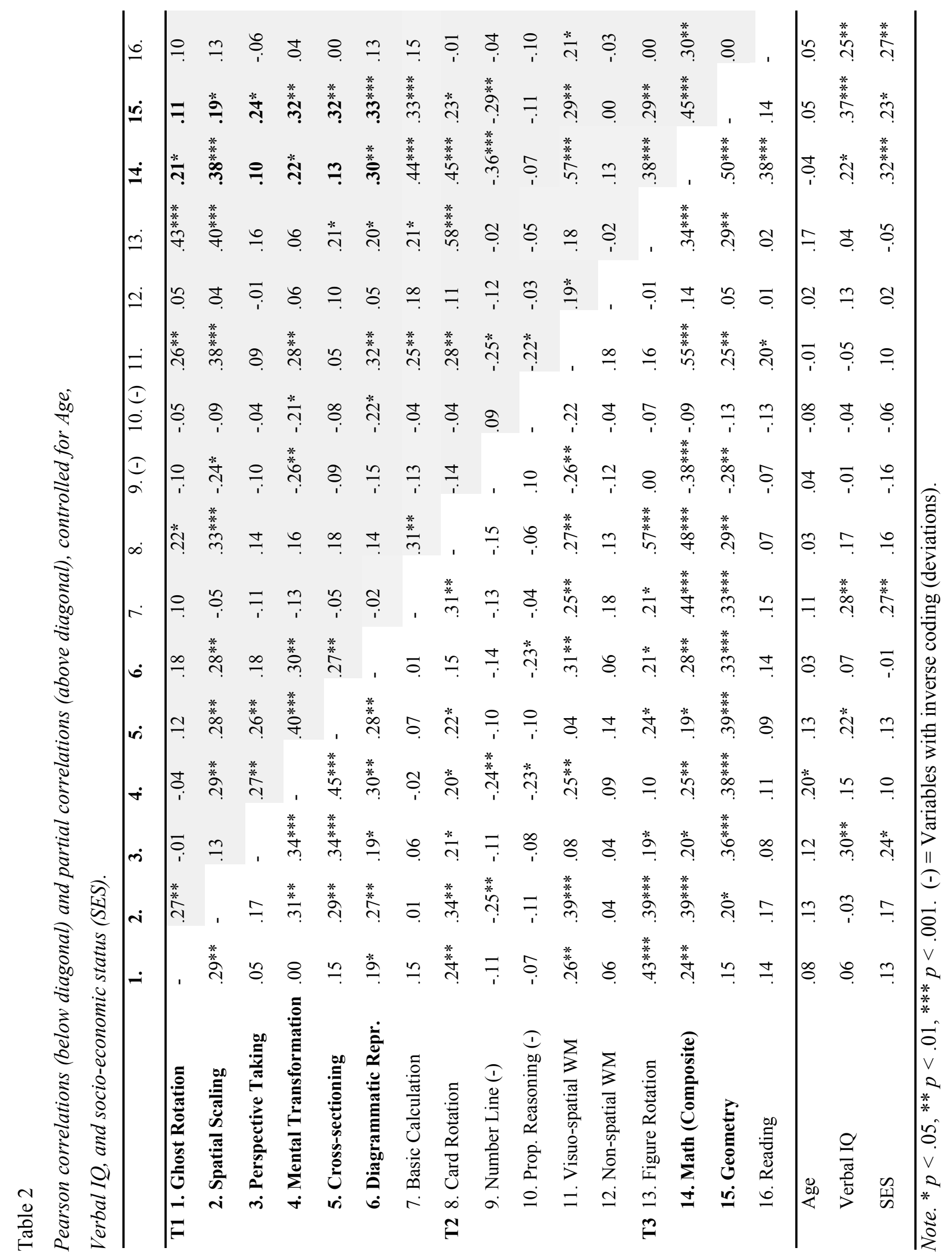


Table 3

Exploratory Factor Analysis

\begin{tabular}{lcc}
\hline & \multicolumn{2}{c}{ Factor } \\
& ST1 & ST2 \\
\cline { 2 - 3 } Ghost Rotation & .695 & \\
Spatial Scaling & .407 & .459 \\
Diagrammatic Representation & .251 & .408 \\
Cross-sectioning & & .597 \\
Mental Transformation & & .723 \\
Perspective Taking & & .455
\end{tabular}

Note: Extraction method: Principal Axis Factoring. Rotation method: Oblimin with Kaiser Normalization. $\mathrm{KMO}=.68$; Bartlett's Test: $\chi^{2}(15)=77.08, p<.001$ 
Table 4

Tested mediator variables (T2) with standardized regression weights and significance levels.

\begin{tabular}{|c|c|c|c|c|c|}
\hline \multirow[b]{2}{*}{ Mediator Variable } & \multicolumn{5}{|c|}{ Indirect Paths } \\
\hline & $\begin{array}{l}\text { ST1 to } \\
\text { Mediator }\end{array}$ & $\begin{array}{l}\text { ST2 to } \\
\text { Mediator }\end{array}$ & $\begin{array}{c}\text { Mediator } \\
\text { to AO }\end{array}$ & $\begin{array}{l}\text { Mediator } \\
\text { to NLSF }\end{array}$ & $\begin{array}{l}\text { Mediator to } \\
\text { Geometry }\end{array}$ \\
\hline Visuo-spatial WM & $.538 * *$ & -.011 & $.270 *$ & $.251 *$ & .021 \\
\hline Non-spatial WM & -.045 & .191 & .070 & -.075 & -.137 \\
\hline Number Line (-) & -.249 & -.135 & $-.224^{*}$ & -.123 & -.102 \\
\hline Proportional Reasoning (-) & -.021 & -.239 & .045 & -.023 & .031 \\
\hline
\end{tabular}


Figure 1

a)
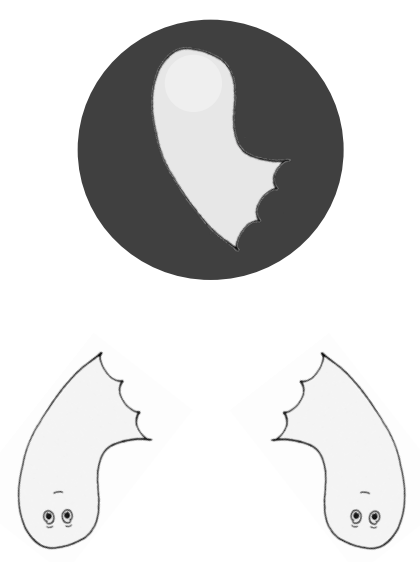

c)

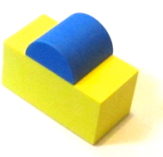

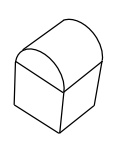
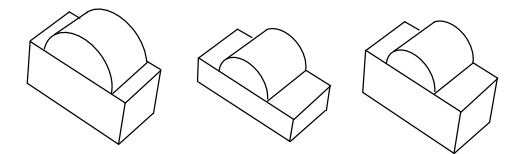

d)
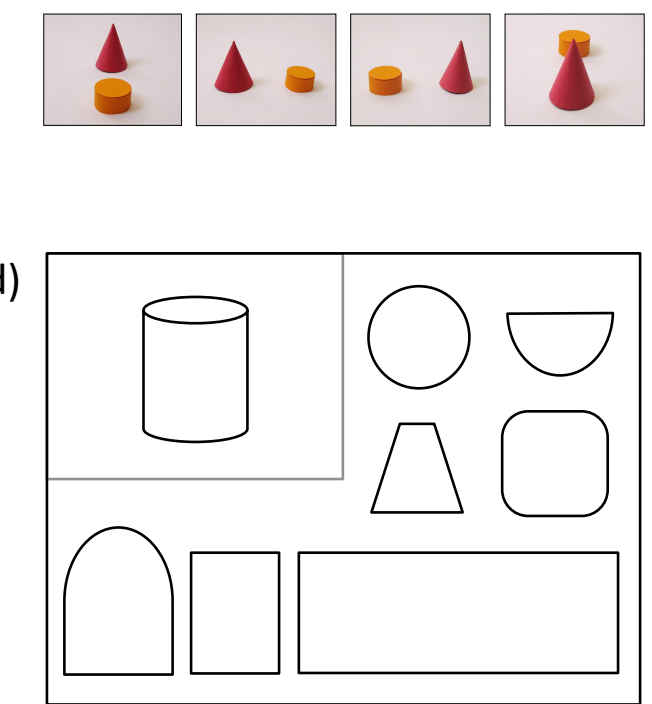

e)

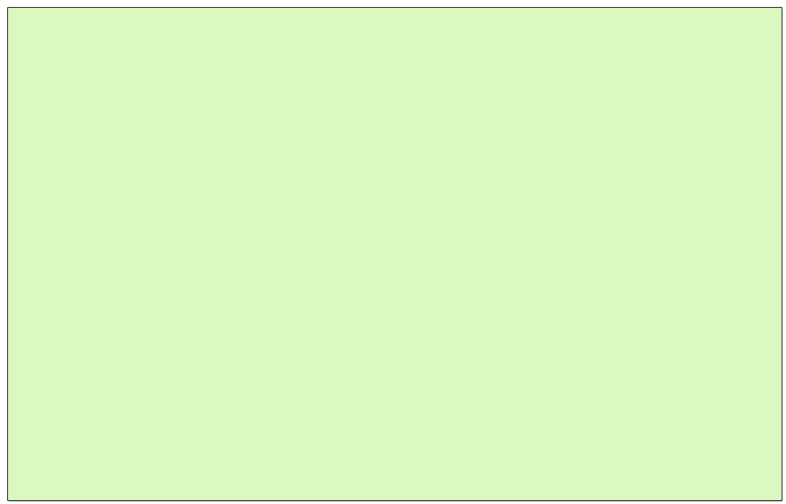


Figure 2

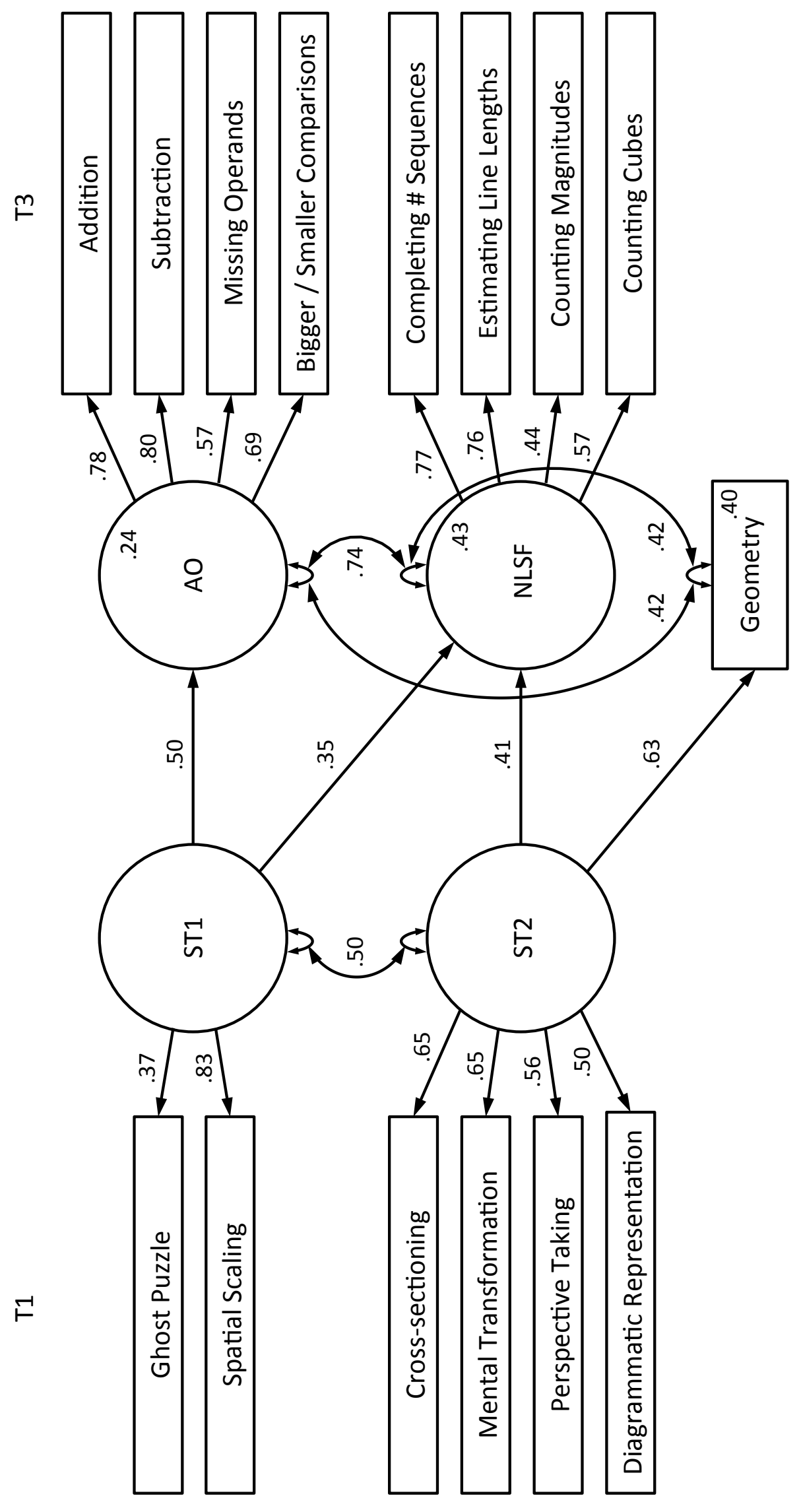


Figure 3

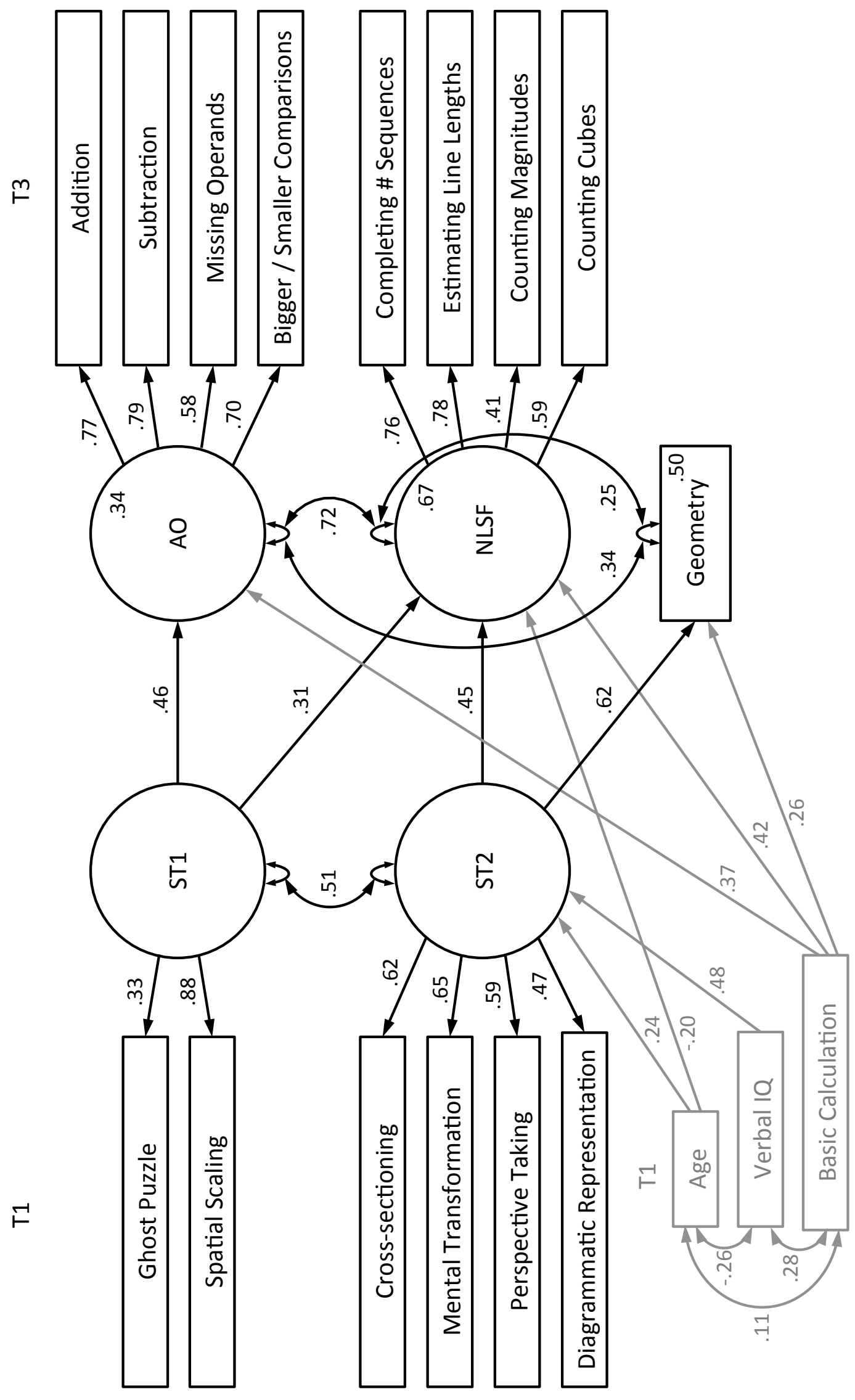

